\title{
A STUDENT MUSIC THERAPIST'S EXPLORATION OF HER CULTURAL IDENTITIES IN RELATION TO MUSIC THERAPY PRACTICE IN A SPECIALIST MUSIC THERAPY CENTRE IN AOTEAROA NEW ZEALAND
}

BY

HEE HYUN HAN

\begin{abstract}
A thesis
submitted to the Victoria University of Wellington in fulfilment of the requirements for the degree of Master of Music Therapy
\end{abstract}

Victoria University of Wellington $(2015)$ 


\begin{abstract}
This heuristic research explores a student music therapist's (SMT's) journey of discovery with respect to her cultural identities in relation to music therapy (MT) practice with clients from diverse cultural backgrounds. A review of the literature was undertaken to investigate issues of identity in relation to MT practice. In order to analyse and evaluate the SMT's experience of working with culturally diverse clients, secondary analysis of the student's reflexive journal was used to identify the relationships between the SMT's cultural identities and her MT practice with clients. Four main themes emerged during the process of thematic analysis of data: experiencing strong feelings as an SMT; observing individual reactions as an SMT and interpreting clients' reactions; making connections and disconnections with clients; and learning to adapt and refine the use of MT methods. The research emphasised how a student can learn about practice and research through reflexive self-examination, and raised awareness of the complex interactions of identities of therapist and client that occur in MT practice.
\end{abstract}




\section{Acknowledgements}

I would like to express my gratitude to people who have helped me throughout this journey:

To Mum, Dad, Aunt and Uncle, for providing emotional, spiritual, and physical support, especially during the times of distress and grief surrounding Dad's operation.

To my research supervisor Dr Sarah Hoskyns for supporting me in my practice and research, and helping me to get through the difficult times.

To the Sir Roy McKenzie Trust for the McKenzie Music Therapy Scholarship for making my placement and this research possible in Auckland.

To the team at the music therapy facility and my clinical supervisor for supporting me throughout my placement and research, and providing me with extra care and encouragement.

To my clients and their families for their generous acceptance of and involvement in this research.

To all my colleagues in Wellington, for your motivation and friendship in addition to our passion for music therapy.

To Andrea for accommodating me in Wellington on my monthly visits.

To Judy for your amazing editorial work and delivering things so promptly and sensitively.

The Massey University Human Ethics Committee gave ethical approval for this research. Application: Southern A Application - 11/41, 15/08/11. 


\section{Table of Contents}

Abstract

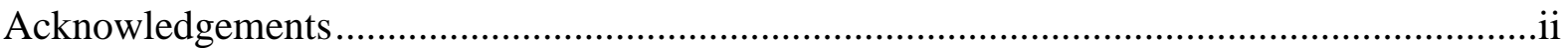

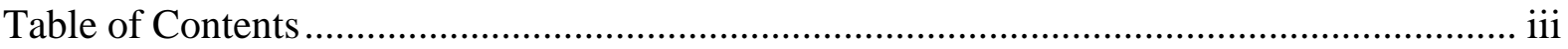

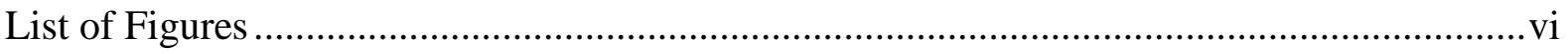

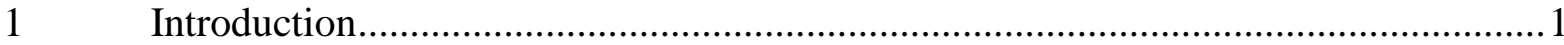

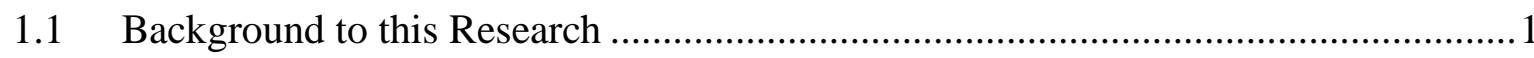

1.2 Research Context and Placements in the Community .............................................

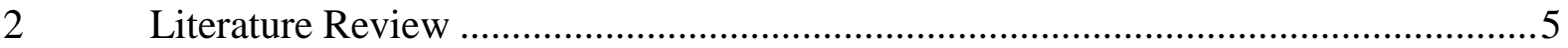

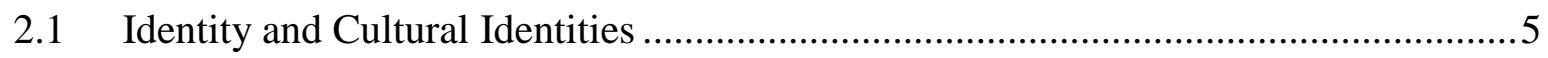

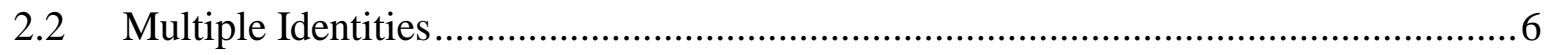

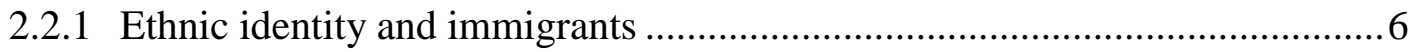

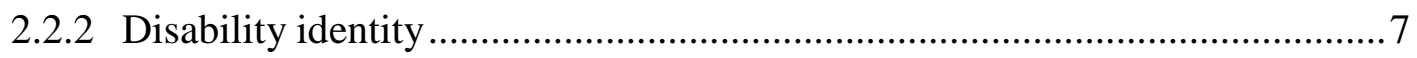

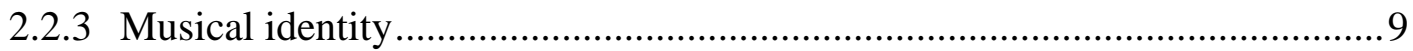

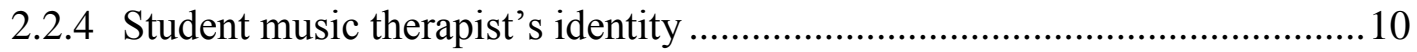

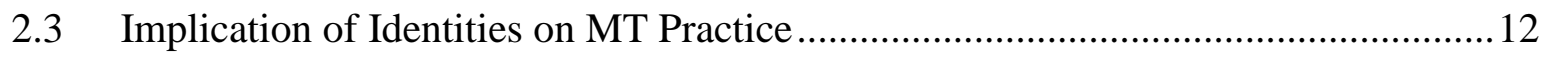

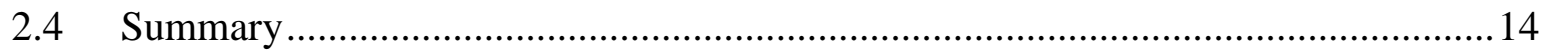

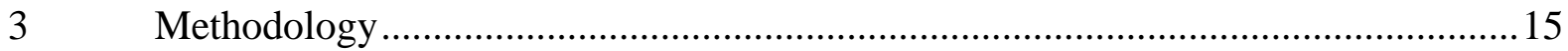

3.1 Research Questions and Aims ........................................................................ 15

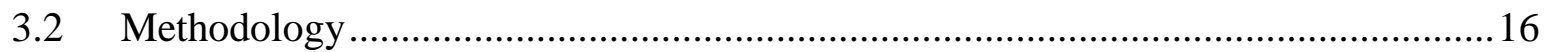

3.2.1 Heuristic research and its relevance in practice ....................................... 16

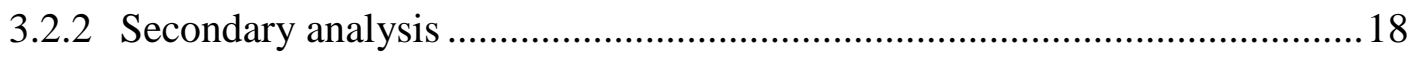

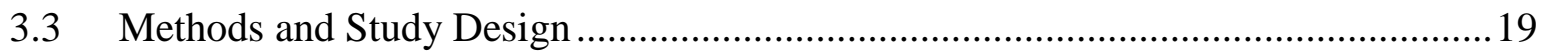




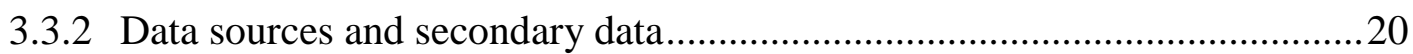

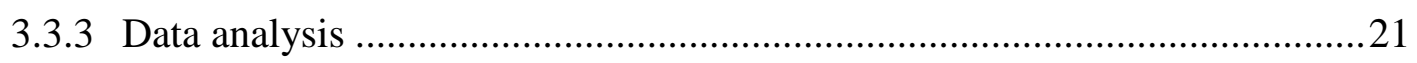

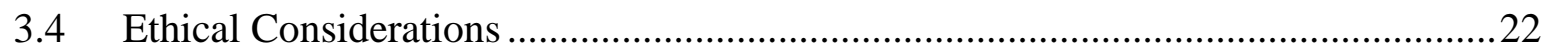

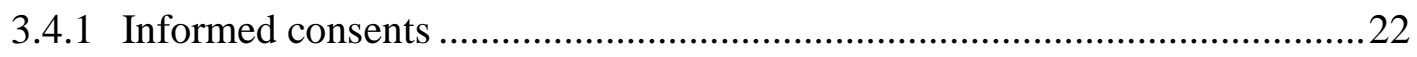

3.4.2 Meeting with Māori student advisor .......................................................22

3.4.3 Code of ethics and ethical approval ........................................................22

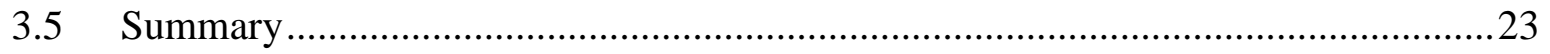

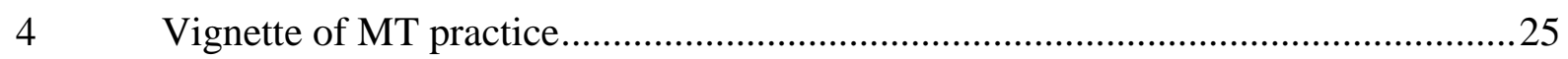

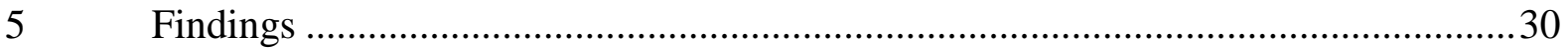

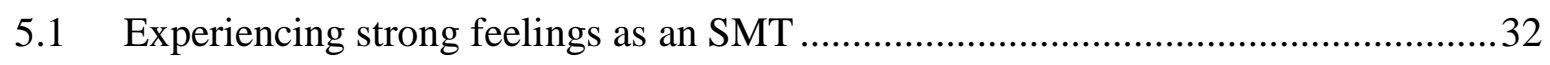

5.2 Observing my own reactions as an SMT and interpreting clients' reactions ............34

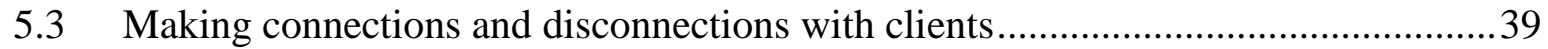

5.4 Learning to adapt and refine the use of MT methods ......................................... 41

5.5 Summary

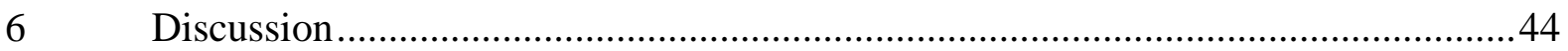

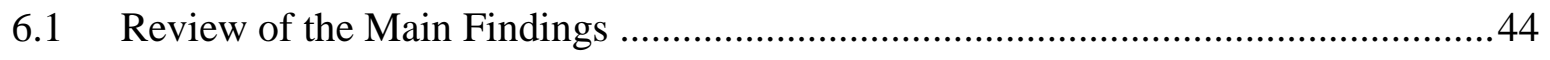

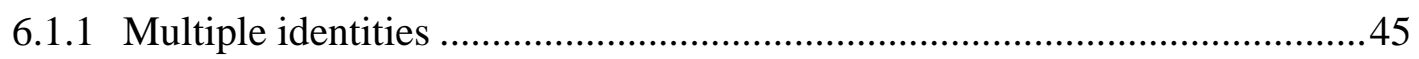

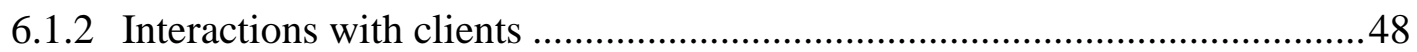

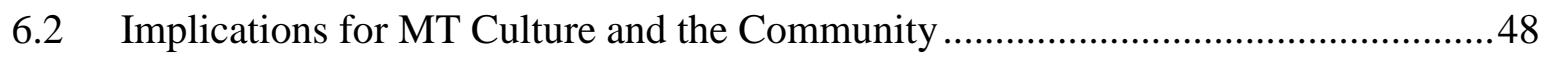

6.3 Reflections on the Research Process and Limitations .........................................49

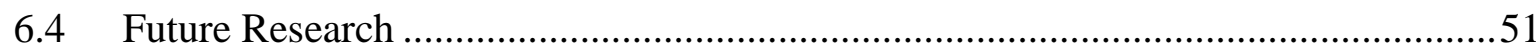

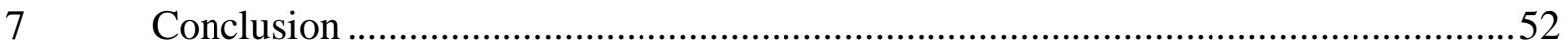


References

Appendices

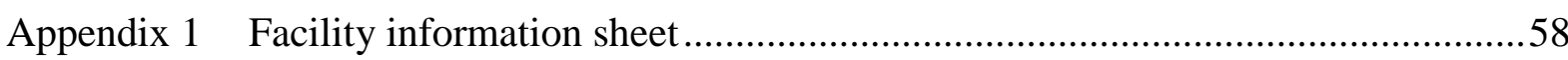

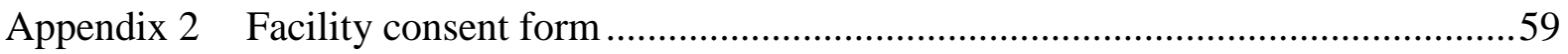

Appendix 3 Information sheet for client's caregiver or family member............................60

Appendix 4 Consent form for client's caregiver or family member ...............................62

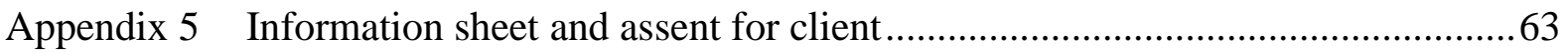

Appendix 6 Information sheet for music therapy clinical supervisor ............................... 64

Appendix 7 Consent form for music therapy clinical supervisor...................................65

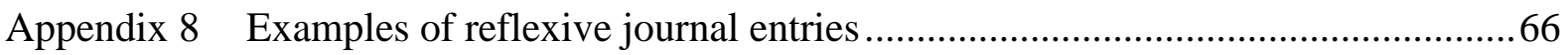

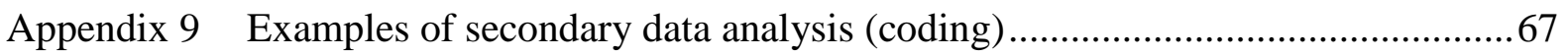

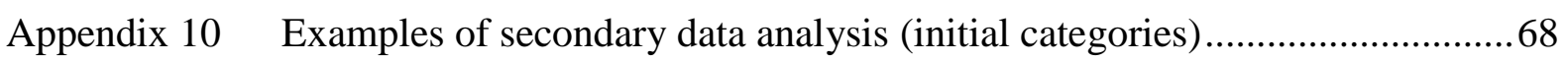

Appendix 11 Examples of secondary data analysis (possible themes) .............................69

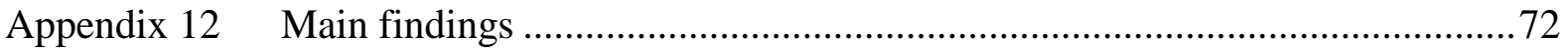




\section{List of Figures}

Figure 1. Ivan Shishkin, “Oaks” 1887. Quotes from Welleran Poltarnees, “An Anniversary

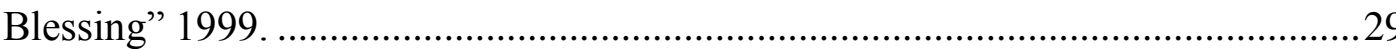

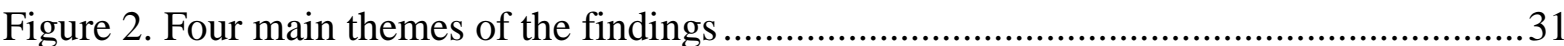




\section{Introduction}

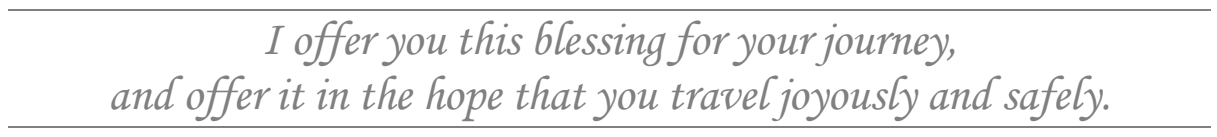

This heuristic research contains a story about 'self' and 'identity.' I, as a student music therapist (SMT) and a student researcher, explore the multiple layers of my own cultural identities, and search for their relationship with my music therapy (MT) work with clients from diverse cultural backgrounds. I perceive myself as having more than one identity: I am a Korean woman embodying 'Kiwi culture'; I am an only child surrounded by 14 sibling-like cousins; and I am an SMT with some knowledge of psychology and a classical music background.

The research has been undertaken as part of the Master of Music Therapy programme at the New Zealand School of Music, Wellington. It aims to analyse and evaluate my journey as an SMT during my practice at a specialist MT centre. I anticipated at the beginning of this research that I would be able to reflect on my own cultural identities and consider the implications of how my increasing awareness of self can deepen my understanding of MT practice in New Zealand. I will be using the first person "I" voice throughout this heuristic study.

During my MT journey, I found a friendly companion book called A Travel Blessing by Welleran Poltarnees. The book kept on speaking to me and I was very much inspired by its message throughout my journey, so I will make references to it in each chapter of this study.

\subsection{Background to this Research}

I am a Korean woman and have lived in New Zealand for 12 years. I was born in Seoul and moved to New Zealand with my family when I was 12 years old. In my youth in New 
Zealand, I observed the great effort made by my parents to stay here in pursuit of a better living environment and educational opportunities for their child. From a young age, I learnt through my family experience how challenging and demanding it is to live and sustain oneself in a foreign land.

When I was young in Korea, I was taught that it is a virtue to be less assertive when communicating with others, and to show little of your emotions but to listen and be considerate of others. Although I grew up in New Zealand from a young age, my Korean values and beliefs coexisted with a New Zealand approach because I was living with Korean family and friends.

During our immigrant life in New Zealand, my family had to move back to Korea several times due to delayed applications for Permanent Resident visas and shortage of funds. When I went back to Korea I experienced not only a physical transition but also transitions in roles, identities, and language. Although it was the place I was originally raised in, I soon became an alien with respect to things that were different to what I had been doing in New Zealand. Some common aspects of New Zealand society, like waiting in line and saying "Excuse me" or "Sorry" are rarely seen in Seoul, since a huge population lives in a small area. Such personal experience can be related to the concept of reverse cultural shock, which Uehara (1986) described as the "temporal psychological difficulties returnees experience in the initial stage of the adjustment process at home after having lived abroad for some time" (p.420).

When I meet with other Korean friends, many of them say they feel strange and even unfamiliar when they visit their home towns in Korea. I assume that this is not because Korea has changed in a strange way but because those who have lived in New Zealand for a long period of time tend to be assimilated or blended into its unique culture and way of living. 
It was my personal experience with immigration struggles, and both cultural differences and cultural connectedness, that motivated me to undertake research on the topic of personal experience and cultural identities. I was interested in the possible implications of my 'self', which consists of more than one single identity, on my MT work with clients who also have their own identities. In addition, I was interested in how being more aware of my identity and hidden values might change the way I work with my clients.

\subsection{Research Context and Placements in the Community}

This research forms part of the requirements for the degree of Master of Music Therapy at the New Zealand School of Music. The study is based on my clinical work as an SMT during the second year of training.

The centre in which I worked and carried out the research is a facility where professional music therapists work together to help individuals and groups with a range of special needs. Individual and group MT services are provided for children and adults. Staff at the centre come from a variety of ethnic cultural backgrounds, including two from Asian cultures, some from Europe, one from South America and some New Zealanders. Clients in the service have varied backgrounds and include a number of Asian children and their families, with whom I may have similar and different experiences to share. Also, learning and practising MT at this facility, which has a strong psychodynamic and self-reflective style of working, has created a synergy between my practice and this particular research.

A number of clinical opportunities were available for student practice at the facility including individual or group MT, co-therapy with music therapists and an outreach MT programme. These options enabled me to work in a broad context with clients from diverse cultural backgrounds, and therefore provided a range of opportunities to study how my own cultural identities can influence my MT practice. During the practicum, I encountered the 'culture' of 
an MT service, cultures of disability and diagnosis, such as cerebral palsy and autistic spectrum disorder, and the cultures of schools and a rest home where I practiced MT. All these opportunities provided me with a chance to reflect on my work as an SMT in a particular place at a particular time. 


\section{Literature Review}

\section{First, get out the 6ooks and maps, then \\ let your imagination run wild, for the journey you conceive is as important as the journey you take.}

The issue of culture and identity has become more prominent in MT practice and research as the clientele has become more culturally diverse (Kim, 2013; Hadley, 2013a). MT research is increasingly exploring cultural and identity issues from the point of view of both therapists and clients (Hadley, 2013a; Wheeler \& Baker, 2010; Brown, 2001; Kenny \& Stige, 2002; Swamy, 2011). In the past, music therapists focused on learning music from other cultures and gaining knowledge of other cultures and customs, whereas in recent years the focus has shifted to increasing the therapist's awareness of self and their own cultural identity, taking into account the role of music in the culture in which the MT is taking place (Darrow \& Molloy, 1998; Wheeler \& Baker, 2010; Stige, 2002). This review presents relevant literature on identity and its implications for MT practice to set the context for the current study.

\subsection{Identity and Cultural Identities}

Identity can be defined in many different ways. In a general sense, it refers to an individual's personal characteristics such as name, age, gender, ethnicity and religion (Ruud, 1998; Sue \& Sue, 2008). Ruud (1998) argues that identity formation is a continual process that is being shaped when we conceptualise "who we want to be and where we want to belong" (p.37). Our identity is also connected to our sense of self, which may shift and change within an ongoing continuous construction and reconstruction process (Ruud, 1998; Thomas \& Schwarzbaum, 2011). It is a process of change that occurs as we grow and gain life experience (Ruud, 1998; Thomas \& Schwarzbaum, 2011). 
Our cultural identity is constructed over the course of time as we experience different social groups (Thomas \& Schwarzbaum, 2011). Erikson (1968), who introduced the psychosocial theory that human development must be understood in relation to each person's culture and life circumstances (Berk, 2007), suggested that our identity concerns not only its core in individuals but also has to be sought in a larger social and cultural context. Ruud (1998) noted that individuals become embedded in a particular way of being within the culture of the group they are in, whether it be a social or an ethnic group. He related an individual's identity to a sense of belonging, and suggested that one's identity can be explored through being more aware of individuals' roles in a social group and cultural group. Thus, being part of a social and cultural group can create new meanings in one's identity (Ruud, 1998).

\subsection{Multiple Identities}

It is important that practitioners, who work with individuals from multiple cultural backgrounds, gain awareness of different social and cultural identities and the implications of their clients' multiple identities for understanding the therapy process (Thomas \& Schwarzbaum, 2011). I chose four types of identities, which seemed to be closely linked with the current study, to review various issues related to identity and their clinical implications.

\subsubsection{Ethnic identity and immigrants}

Ethnic identity is our first source of identity as we grow up. Thomas and Schwarzbaum (2011) explained that the culture of the family plays an important role in the formation of ethnic identity. Individuals in a family may develop identities that are strongly influenced by implicit family norms and values (Thomas \& Schwarzbaum, 2011). When a family moves from its home country and emigrates, each member is affected by the constant stress of adapting to a new culture and lifestyle (Gilboa, Yehuda \& Amir, 2009). Cominardi (2014) studied this trans-cultural process during MT with immigrant children in Italian 
kindergartens, and found that they had difficulties in relating to their peers and teachers and had a low sense of autonomy and self-esteem.

The issue of ethnic identity is actively studied by researchers who examine the experiences of immigrants. Swamy's (2011) MT research illustrated the concept of multi-dimensional identities, in which immigrant individuals and communities may move back and forth between their home land and a foreign land and go through shifts in their multiple identities and roles. During their journey, immigrants may explore different abilities in negotiating and adopting new identities within various social and cultural contexts. This perspective suggests that identities are flexible, fluid, and reconstructive.

Immigrants always face challenges about whether or not to redefine their identities in a new environment (Thomas \& Schwarzbaum, 2011; Gilboa et al., 2009). Regardless of how quickly immigrants go through the process of cultural assimilation or acculturation, with or without being conscious of it, they learn to redefine their cultural identities at both the individual/family and social levels (Thomas \& Schwarzbaum, 2011).

\subsubsection{Disability identity}

The process of adjusting to a disability is not vastly different from that involved in dealing with immigration. Models of disability identity development indicate that individuals with various ability statuses can go through stages of awareness of their disability to a state of acceptance (Gibson, 2006). During that process, individuals with disabilities need physical and emotional support to adjust to their new identity (Thomas \& Schwarzbaum, 2011).

For people who experience a change in health status and acquire a disability or illness during or after the process of adjusting to their circumstances - they may establish a new identity in various ways, including learning about their condition or disability and getting 
support from professionals and the community. Anthony (1993) explained that recovery for people with mental illness is a unique and personal process that changes attitudes, values, feelings, skills and roles. In fact, people with psychiatric illness may develop their own ways of living with the disrupting experiences. For example, one of the participants in Sullivan's (1994) study described his ways of dealing with hallucination; "When I threaten them bad enough [the voices], usually they try to get worse with me, but if I just make it serious enough [his threats], they will leave me alone.” (p.22).

Despite their efforts to overcome challenges and adapt to a new life style, people with a disability may confront different obstacles from a range of external influences. Gething (1997) pointed out that people with mental illness experience confusion and their sense of self-worth and self-esteem can be influenced by the attitudes of others. Nettles \& Balter (2012) addressed a range of challenges that Deaf people may face in their community. They explained that Deaf people often find themselves struggling to split their social identities from their disability identities because of the misconceptions about communication. For example, Deaf people communicate differently using spoken language, signed language, gestures, mime, and in writing. However, people often do not recognise that a signed language can be as effective - if not more effective - than spoken language in conveying the intrinsic meaning or nuances of the message (Nettles \& Balter, 2012). As a consequence, Deaf people experience a shift in their multiple identities depending upon different social situations and demands (Nettles \& Balter, 2012). To give another example, one of the Māori Deaf interviewees in Smiler and McKee's study (2007) reported that he felt the need to integrate both his Māori and Deaf identity into his sense of self in order to interact with both his own community culture and Deaf culture.

Thinking from the client's perspective and learning about social demands that they might be experiencing can be helpful in improving our understanding of MT work with clients with 
different disability identities. As Thomas and Schwarzbaum (2011) pointed out, understanding different issues related to disability identity, such as how people with disability deal with their illness and establish a new sense of self, may help therapists to gain more knowledge when they work with clients who have differing ability statuses.

\subsubsection{Musical identity}

Music can play an important role in the formation and restoration of identity in various settings. The issue of musical identity can be found from MT work in palliative care settings or with immigrants because of its unique power to allow participants to rediscover and restore their identity through various means (Aldridge, 1995; Gilboa et al., 2009; Kim, 2013; Christobel \& Baker, 2009).

Because music transmits the emotions and worldview of people at a particular time in a particular place to the next generation, it can represent social identities, aspects of social organisation and the unique history and heritage of a social group (Amir, 2004; Kenny \& Stige, 2002). Gilboa et al. (2009) described our musical preference as a reflection of our childhood, ethnic group, religion, and culture, and thus it defines who we are and where we belong. Thus, people can demonstrate their identities and share cultural issues and experiences by presenting their own music to listeners.

Amir (2012) illustrated the concept of Musical Presentation (MP), which has the purpose of increasing the self-knowledge of clients and students. The main idea is based on the belief that music represents individuals' identities. With MP, music can be shared with a group of people by presenting a collection of meaningful music and songs that have been chosen and recorded on a $\mathrm{CD}$. It involves listening to, performing and talking about the music. In this way, group members can get to know each other and share life experiences and memories. 
The issue of identity has a significant part in a palliative care work. Music is used in various creative ways to promote and recreate the identity of people whose lives are challenged by their illness (Forrest, 2002). Aldridge (1996) explained that music therapists working with patients with a terminal illness, who have experienced a loss of identity, can use music "to explore and express their being in the world" and rediscover their identity through music (p. 261).Thus, music can support the needs for humans to know and feel comfortable with who they are and what they might be able to do, which may also contributes to their sense of selfacceptance and self-actualisation.

Ruud (1998) pointed out the importance of issues of music and identity in MT. He asserted that music therapists need to be aware of their own musical identity and understand the role of music in their lives in order to increase sensitivity to their own cultural background and personal history. Also, understanding the role of music in constructing an individual's identity and self-concept can help therapists to use the right music and approach for their clients (Ruud, 1998).

\subsubsection{Student music therapist's identity}

During their MT training, students may go through new challenging experiences that change their identities, self-perception, and ways of perceiving others. Being a student can create not only a lot of learning opportunities but also challenges and anxiety stemming from unfamiliar experiences. For example, Wheeler (2002) interviewed MT students and discovered six main areas that reflected students' experiences: challenges encountered by students; means of dealing with challenges; involvement with clients; areas of learning; supervision issues; and structure of MT practicum. Her study suggested that students underwent different challenges that stemmed from their concerns about new experiences, planning the sessions, dealing with different levels of clients' needs, their music skills, and the grading aspects of the practicum. 
MT students may have multiple identities besides their student identity. These identities can be re-experienced and redefined during MT training. McClain (1993) surveyed MT students on their self-perceptions during their MT training and found that the students felt most competent first as a person, then as a therapist, and finally as musicians. Students felt their musician's identity was the weakest self because of poor skills and great anxiety when playing musical instruments and in other musical skills such as sight-reading, playing by ear, transposing and improvising. They felt more competent with their therapist self as they had learnt to deal with various situations, tune in to clients communication, and show their sensitivity and understanding. Finally, students felt most competent as individuals because they became more self-assured and independent during the training.

Anxiety that comes from new experiences and not knowing about clients or MT work often challenges many students, but Edwards and Daveson (2004) suggested that it may help students to review their identities and learn how their identities and past experiences impact on their MT work. They explained how students' experiences of anxiety, feelings of insecurity, resentment, and anger may challenge their ability to separate personal from professional roles. However, this may prompt the students to review their identities and learn about the implications of their past experiences on their MT. Edwards and Daveson (2004) proposed as an example a student who begins MT training with an excellent classical music background, and explained that the student's self-image as a competent classical musician may be challenged as the student learns how to use music functionally, in a spontaneous way, with specific client groups. Eventually, the student may review their previous way of playing and adopt a new musical identity to develop therapeutic musical skills (Edwards \& Daveson, 2004). 


\subsection{Implication of Identities on MT Practice}

The importance of increasing music therapists' awareness of self and identity has been discussed by many authors (Hadley, 2013b; Brown, 2001; Rickson, 2010; Kenny \& Stige, 2002). Therapists bring their identities and cultures into MT as do their clients (Kenny \& Stige, 2002). For example, in her microanalysis study of meaningful moments with children receiving MT, Johns (2013) noticed that the way she listened to the music was influenced by her background of being trained as a jazz musician and her past experience of transcribing music.

In some other situations, therapists find a new identity that emerges from their specific role or particular clinical situations. For example Gadberry (2014), in her research about her own experience providing MT in a foreign country, reported that working in a new environment and the various challenges that came from meeting with new people extended her sense of independence and confidence as a person and as a music therapist. She also explained that she found a new sense of self and gained new insights and a deepened appreciation for her work.

Hadley (2013b) discussed music therapists' personal and professional identities, and how different aspects of music therapists' identities can impact on therapeutic relationships. She pointed out that our identity is formed by our gender, race, age, ability, sexuality, socioeconomic status, religion, geographic location and other influences that exist around us and in our daily practice, thus making it difficult to separate personal identity from professional identity. As an example, in her study about home-based paediatric palliative care with children and families from diverse cultural backgrounds, Forrest (2014) recognised the importance of acknowledging the implications of her cultural background on the therapeutic 
relationship. She noticed that her age, gender, where she come from, family background, beliefs and multicultural experiences influenced the way she worked with individual families.

It is very valuable for therapists to explore different aspects of their identities and selves, as these aspects will affect not only themselves but also their clients (Hadley, 2013b). Also, therapists need to understand how their own feelings, attitudes, actions, and their inner being, can impact on the client and the therapy process (Hadley, 2013b).

In art therapy, Maat (2011) explained that therapists' multicultural competency begins when they seek cultural self-awareness. It involves asking themselves questions such as: who are they as a cultural being; how do they see themselves in relation to the natural and spiritual world; where are they in terms of racial identity; where do they belong; and what are their cultural norms and values. By gaining self-knowledge and more awareness of their own cultural identities, therapists can become more sensitive to their clients' cultural identities (Maat, 2011).

In psychotherapy and counselling, cultural knowledge is not the only requirement for a therapist's cultural competency (Bradt, 1997). Therapists' awareness of their own assumptions and values come first and cultural knowledge and skills come next (Sue \& Sue, 2008). To become culturally aware, therapists need to move from "being culturally unaware to being aware and sensitive to [their] own cultural heritage and to valuing and respecting the differences" (Sue \& Sue, 2008).

Brown (2001) asserted that examining one's own worldviews and assumptions is crucial since we tend to understand others through our own worldview, which is informed by our own cultural background. In fact, a client's beliefs about their illness and emotional issues can be different from that of the therapist (Bradt, 1997). As Sue and Sundberg (1996) noted, it is not easy to identify and question our own cultural identities and worldviews and 
recognise their implications as they are "so deeply ingrained" in our values (cited by Brown, 2001). Therefore, therapists' self-knowledge about their own attitudes and feelings can help them to become more aware and sensitive when working with culturally diverse clients (Bradt, 1997; Brown, 2001).

\subsection{Summary}

The subject of culture and identity is gaining more awareness from MT researchers and practitioners as they encounter increasing numbers of clients from diverse cultural backgrounds. In this chapter, identity has been discussed as both an individual's personal characteristics and also as a set of beliefs and values that are constructed from being part of larger cultural groups and the community. For MT trainees, it can be valuable to gain knowledge about their own identities including their student identity. Furthermore, understanding the client's disability identities as part of their cultural identities can provide music therapists with new perspective on their MT work with clients who have differing ability statuses.

On the other side, examining cultural diversity in relation to ourselves as music therapists can be as important as understanding that of our clients, because diversity has always been there and we are working with people who have diverse experiences to us.

It is important for MT practitioners to be aware of their own multiple identities as well as their clients' in order to improve understandings of their impact on the therapy process. In order to do that, they can study their identities by using qualitative research methods. The literature indicated that self-reflective work by students increases sensitivity to important issues for participants in MT, hence I decided to embark on a research project using heuristic methodology. The next chapter of the exegesis explains this approach. 


\section{Methodology}

Travel lightly - carrying neither weighty luggage

nor burdensome preconceptions.

\section{Expect the unexpected,}

for those who travel rigidly will find much to distress them... while those who travel flexibly will have many and varied adventures.

Qualitative research methods were employed in this study in order to explore the nature of an SMT's own cultural identities and their relationship to MT practice with clients from diverse cultural backgrounds. This approach allows the value and meaning of the experiences of the researcher to be discovered and explored through descriptive and interpretive understanding of experiences (McLeod, 2011; Wheeler, 2005; Ruud, 1998).

Qualitative research techniques enable the researcher to be flexible and sensitive when generating and analysing data (Lichtman, 2013). Qualitative methods allow the researcher to become immersed in the data and work out what it might mean by analysing the data in a way in which meaning is constructed (McLeod, 2011).

\subsection{Research Questions and Aims}

In this research, I asked and reflected on one main broad question:

How does an SMT's exploration of her cultural identities relate to her work with clients from diverse cultural backgrounds?

I expanded this main question by defining two phrases:

SMT's exploration of her cultural identities = a systematic, self-reflective way of looking at the SMT's cultural identities and aesthetic self that include her ethnic heritage, social and life characteristics, and musical self. 
MT work with clients from diverse cultural backgrounds $=\mathrm{MT}$ work that is client-centred, focusing on building relationships with clients from diverse cultural backgrounds and social circumstances, who have different life experiences, living environments, and varied health conditions or abilities.

Combining the main points from each phrase created another perspective on the research question which created a sub-question:

How can my awareness of self and exploration of own cultural identities deepen my understanding of MT with clients from diverse cultural backgrounds?

This qualitative study aimed to analyse and critically evaluate my journey as an SMT working with clients with diverse cultural histories during my practicum experience at an MT facility. It was anticipated that I would be able to reflect on my own cultural identities and worldview through the MT work and consider how such awareness can support and deepen understanding of MT practice in New Zealand.

\subsection{Methodology}

3.2.1 Heuristic research and its relevance in practice

The term "heuristic" originated from the Greek "heuriskein" meaning 'to find, find out, discover, devise, invent, procure' (Higgins, 1996). In heuristic research, the focus is on the researcher's journey and reflexive experience of discovery that contributes to growth in the researcher's self-awareness and self-knowledge (Higgins, 1996; Gilroy, 2006).

Heuristic research was developed by Moustakas (1990), and is a process in which one studies one's own encounters with the phenomenon of interest by identifying with the phenomenon through empathic experience, dialoguing with oneself, searching for what one already knows, using one's intuition, indwelling in the experience with unwavering attention, 
clearing oneself to focus, and relating to an internal frame of reference (Moustakas, 1990). By using this method, researchers can gain deepened understanding about themselves and develop greater insight into and appreciation of their experiences.

In recent qualitative research, the emphasis has been on the researcher's reflexivity and selfawareness to highlight the use of personal and subjective experience (McLeod, 2011). While researchers use their experience as data to study the phenomenon, the focus is on the researcher's ability to use his or her experience to represent the relationship between the nature of human experience and the experiences of others, who could be MT clients in this context (Wheeler, 2005; Tesch, 1990; Gilroy, 2006). There is a particular relevance in this approach for investigating the therapist's interest in relationships and awareness of understanding of his or her own reactions (Smeijsters, 1997). In the same way, a student's learning about self and emotional responses is an important part of the journey (Baker \& Krout, 2011). In relation to this particular research, a heuristic research method offered a framework for using my own reflections on culture and MT practice in a rigorous and ordered way.

In MT, the therapist's self-awareness may be encouraged through supervision, writing a journal, personal therapy and practising self-care (Dileo \& Loewy, 2005). A therapist's selfawareness may include the awareness of feelings, beliefs and needs and how they are different from those of clients; understanding of one's motivations; willingness to feel pain and loss; a commitment to one's inner growth; confidence in one's instincts; the ability to set and accept limits; acknowledgement of the importance of self-care; and identification of one's own culture as it relates to the client's culture (Dileo \& Loewy, 2005). 


\subsubsection{Secondary analysis}

Secondary analysis is a methodology used by social researchers in which they re-use preexisting data with the purpose of answering new research questions (Heaton, 2004).

Researchers can look back at data gathered from earlier clinical practice and interpret them from different perspectives. In this way, data can be thoroughly reviewed and can produce new knowledge and insights (Heaton, 2004). One of the advantages of this method of data gathering is that the researcher can explore a topic from a practice without diverting from their usual approach and activities as a practitioner, and still produce new interpretations (Heaton, 2004). In this way, researchers can carry out their research without involving human participants and be safe from ethical conflicts. It is particularly appropriate for students undertaking practice-based research.

In this study, secondary analysis of the student's reflexive journal was used to identify the relationships between the SMT's cultural identities and her MT practice with clients. This enabled the analysis and evaluation of the SMT's experience of working with culturally diverse clients. The ongoing reflexivity about my practice, was somewhat limited by secondary analysis methodology, as I was looking back at work completed, and could not actively engage with developing my practice and research as I went. Nevertheless, the presence of my reflexive journal invited me to write observations about my topic, which in turn encouraged more insight and understanding. The reflexive approach did become more developed in the research analysis, 'bending back' on my ideas about the practice as I tried to understand my motivations and client expressions in a more meaningful way. 


\subsection{Methods and Study Design}

\subsubsection{Self-reflexivity and reflexive journal}

Reflexivity is used and defined by many researchers and practitioners. Etherington (2004), a counsellor and researcher, explained that reflexivity is "the capacity of the researcher to acknowledge how their own experience and contexts inform the process and outcome of inquiry" (p. 31). That is, reflexivity involves the ability to recognise our own responses to other people and events, and to use that knowledge to guide our actions, communications and understandings during the process of research and/or practice. Etherington (2004) also differentiated reflexivity from reflection in practice. Whereas reflection involves knowledge from past experiences by "using what we already know about ourselves", reflexivity is about listening to our inner stories as we listen to those of our clients (Etherington, 2004, p.28). Stige (2002) suggested that in MT, reflexivity can conceptualise the connections between individuals. There were two separate applications of self-reflexivity in this project, in which I used reflexivity both as an SMT in my MT practice and as a researcher during the research process.

Throughout the clinical practice, I kept a reflexive journal that included my own thoughts and ideas about musical interactions and clients' responses. The journal allowed me to reflect specifically on experiences in my practice in a day-to-day way and to interrogate attitudes and assumptions that emerged gradually during the process. Barry and O'Callaghan (2008) observed the value of SMTs using reflective journals to reflect back on clinical notes and experiences developed as part of their regular duties during placement in hospitals, schools or community settings. They noted it provoked deeper understanding of practice choices and decisions and encouraged students to develop insight, self-awareness and analytical thinking. 
In a research context, reflexivity can be a useful methodological tool in heuristic research, where it can bridge between research and practice (Etherington, 2000; 2004). Bowtell and her colleagues (2013) illustrated the use of reflexivity for the provision of emotional safety in qualitative research. They suggested that using reflexivity in research process enabled them to recognise their own emotional responses to the data, the environment and the participants, thus providing the opportunity to think ethically about their research process.

In this research, reflexivity was used during the process of data analysis, interpretation, and self-reflection on my role as a student researcher. Using self-reflexivity allowed me to think about how recognising my role as a researcher could influence each part of the research. It became evident during data analysis and interpretation of data that I was using myself as a tool to search for meanings from the data. As Stige (2002) and Lichtman (2013) discussed, it is essential for reflexive researchers to be aware of how bringing themselves into their research can affect the construction of meanings and concepts from that research.

\subsubsection{Data sources and secondary data}

I worked 2.5 days per week at the MT facility and in a number of outreach settings.

Throughout the practicum, I kept a reflexive journal that included my own thoughts and ideas about musical interactions and clients' responses and how these related to the research question. Entries in my reflexive journal were recorded from 10/03/14 to 24/09/14. Data collected from the reflexive journal consisted of information gathered from a range of clinical work, observational records, and transcripts of verbal and musical interactions. Questions that I asked myself in my reflexive journal were:

- What feelings and thoughts are generated during MT practice?

- Why am I feeling and thinking in such ways?

- Who are connected with my experiences and how?

- What events and situations influence the way I find and interpret the meaning of the experiences? 
- Are there any other related issues outside MT with clients that influence my reflections?

The data-gathering process in qualitative research is different to that in quantitative research.

Epstein (2010) noted that data sampling in qualitative studies is guided by the unique question that is driving the study, rather than the search for representativeness or external validity that is often prioritised in quantitative studies. In self-study as heuristic research, researchers need to ensure that they achieve internal discovery by using personal and subjective experiences, presenting evidence of transformation, and finding access to tacit knowledge (Sela-Smith, 2002).

\subsubsection{Data analysis}

The data was analysed using thematic analysis, a common approach to the analysis of qualitative data, in which the researcher codes each part of the text in the data into relevant themes that emerge during the analysis (Schwandt, 2007). Data analysis methods in this study were informed by Braun and Clarke's (2006) thematic analysis. The adapted process of thematic analysis as used in this study is presented below:

(1) Familiarising myself with the data - I spent considerable time reading and re-reading all of the entries in my reflexive journal. I attempted to immerse myself in the data so that I could understand the content from a researcher's perspective. Then I searched for interesting points or patterns that appeared to be relevant to the research topic, and recorded them in analytic memos while reading the data.

(2) Generating initial codes - Initial codes were produced during the active reading of the data set. Then I developed a list of initial codes by coding each item manually. Some items fitted more than one code. In this case, I coded them as many times as was relevant to the research topic. When an item seemed interesting but did not generate any code, I still recorded it in an analytic memo so that I could go back to it after more codes were produced.

(3) Searching for themes - After I obtained a full list of initial codes, I sorted them into meaningful groups to locate any potential themes. I used mind maps to visualise different categories and create an overarching theme. During this process, a number of potential themes and sub-themes were created. Sometimes I had to go back to the journal and recapture the context if the codes brought up ambiguity about their meanings. I also included a "miscellaneous" category for some codes that did not fit 
into any categories.

(4) Reviewing themes - Codes were reviewed thoroughly to make sure each item cohered within the potential main themes and sub-themes. Then themes and subthemes were reviewed and refined to present the meanings of data concisely. As a result of the review, one of the main initial themes was transformed into a sub-theme of another main theme, where it seemed more appropriate.

(5) Defining and naming themes - Finally, the themes began to uncover meaningful stories about the data. This enabled me to identify the main idea of each theme and the entire findings, and explain them in relation to the research topic.

\subsection{Ethical Considerations}

\subsubsection{Informed consents}

Two different informed consents were gained: from the facility for reviewing of clinical data documented in my reflexive journal) (Appendix 2); and from the clinical supervisor for materials from clinical supervision (Appendix 7). Some of the materials from clinical supervision were recorded in my reflexive journal and treated as research data.

Informed consents from a client and caregivers were gained (Appendix 4), whose MT records were reviewed during the research for clinical vignettes. An informed assent was also sought from the client due to the client's inability to communicate verbally. Although a written assent was provided (Appendix 5), I also explained about the research in person and used 'thumbs up/down' to seek the client's physical permission.

\subsubsection{Meeting with Māori student advisor}

I visited a Māori student advisor at Massey University’s Albany Campus to seek advice about ongoing cultural competence. I was able to ask questions about working with people from different cultural backgrounds and also learn about the current status of Māori and their culture in New Zealand. The advisor also talked about a number of important ideas such as turanga waewae (the sense of belonging, literally "home ground" or "a place to stand"), 
partnering with Māori, and implementing and acknowledging the Treaty of Waitangi into practice. This meeting increased my awareness of the ongoing need for professional respect for clients in research, and of the value of collaborating with Māori about music therapy research and practice.

\subsubsection{Code of ethics and ethical approval}

This study was approved by the Massey Human Ethics Committee: Southern Application 11/41, 15 August 2011, under a template for ethical approval for student practice-based research.

I abided by The Code of Ethics for the Practice of Music Therapy in New Zealand (New Zealand Society for Music Therapy, 2012) and the Code of ethical conduct for research, teaching and evaluations involving human participants (Massey University, 2010) throughout the research process.

I considered carefully how to minimise risks to both the clients and myself as a student researcher. However, as MT is still quite rare in New Zealand and some specialist facilities are unique to main centres in New Zealand, it is possible that the settings could be identified. I have made every attempt to disguise locations and the names of placements or clients involved in this research.

\subsection{Summary}

Self-reflexivity was used during my MT practice and research process. I kept a reflexive journal and recorded my own thoughts and responses in the various forms of interactions with my clients. By doing this, I was able to reflect upon my experiences with clients and interrogate my own attitudes and assumptions. During the research process, I used reflexivity to examine my own reactions and emotional responses to the data. I kept memos as the 
analysis progressed, and these helped me to be more informed and to develop insight about my coding and to better understand my approaches to practice. The reflexivity I felt developed my understanding of the meaning of research and practice. This allowed me to become more sensitive through the process of data analysis and interpretation, which supports the validity of my findings. Thematic analysis of the secondary data allowed new insights and knowledge to emerge from the thorough examination of data in my reflexive journal. A number of themes and categories emerged during the thematic analysis, which I have arranged into four main themes and the subsequent sub-themes and categories. A clinical vignette in the following chapter will illustrate an example of the interactions and process of building relationship with one of my MT clients and provide some references for the materials in the findings. 


\section{Vignette of MT practice}

Open yourself so that you apprehend fully,
deeply and sympathetically.
Remember that wise travellers seek to fully receive
the spirit of each place.

Mary (pseudonym) is a Samoan woman in her 70s. She is not able to speak or move freely as the result of a stroke, but she can communicate yes or no with her eyes and small hand gestures. She was referred for individual MT to work on her self-expression and improve her quality of life. The main focus during MT with Mary was to encourage her communication through music making and to reduce anxiety and agitation while increasing pleasure and satisfaction. She was very responsive to music and often engaged readily in various music-making activities with me.

\section{Session 1-3}

During the first few sessions, I brought a list of well-known hymns as I had been advised that she was a religious woman and would respond positively to hymns. She seemed happy to listen to any hymns that I played for her rather than making choices or initiating other activities. There were quite a few hymns that I could sing in Korean. When I asked her if she wanted to hear one of them, Mary responded by nodding her head and paying full attention throughout the whole song.

By session 3, Mary and I were communicating more actively with each other. She would vocalise to alert me or to sing with me. She would also express her preference for musical instruments and play them slowly and gently with me while I played the guitar. Although there was no significant difference in her physical movements, I could feel her sense of liveliness and enthusiasm about expressing herself and communicating with me. 
Mary looked very tired in some sessions, and sometimes she was having a nap when I came for her MT session. I often tried to wake her up gently by calling and singing her name, accompanied by the guitar. If she was too deep in sleep, I still stayed beside her and played a few slow hymns softly. If she woke up and noticed me, I greeted her and explained what we could do so she understood what was going to happen.

In one session, I played a list of familiar hymns as usual, but Mary changed her face as if she was frowning. I stopped singing but tried to think of other songs while still playing a tune on the guitar. When I introduced her to Summertime, which is non-religious music, Mary opened her eyes and showed her interest. She did not seem to be irritated by my song choice. I improvised on the Summertime tune and sang about asking how she was feeling today. From this session, I learnt that she could respond to songs other than just religious material, and I began to include more variety in our repertoire ${ }^{1}$.

Over the course of the sessions, Mary and I explored various ways of interacting through music. She became more active in initiating activities such as hand dancing and playing solo on the guitar. She used her hands, fingers, eyes, and voice to express herself through music. For example, when I sang a song on the guitar, Mary would listen to it first and then she would join in by vocalising softly but in a particular rhythmic pattern. This would guide us to sing by improvising, which was often led by Mary's directive vocalising.

\footnotetext{
${ }^{1}$ I included at least one song from each culture that I thought we identified ourselves with, for example, Ua Fa'afetai from Samoan culture, Jesus Loves Me from Mary's religious culture, Daisy Daisy from Mary's extra interests, and a Korean lullaby from my culture.
} 


\section{Session 12-19}

Mary enjoyed directing her music while I accompanied her with other instruments. She particularly liked to play the guitar. As soon as I brought it out of the bag, she would immediately approach it and express her desire to play. As soon as she began to strum it softly but with energy, I improvised singing to reflect her playing. She played the guitar in a variety of ways: trying different rhythms and tempi, strumming and picking. When she finished, she pointed at me as if she wanted me to continue to play on the guitar for her. We took turns on the guitar and sang together.

The way we greeted each other also changed. Mary initiated her way of greeting by shaking hands energetically, kissing on my hand lightly and then bringing it to her chest. At first, I felt a bit confused and did not know what to do, but later on I came to understand this as her way of showing appreciation and expressing her warm personality. Afterwards, this became our normal greeting routine and I no longer felt uncomfortable with it.

Towards the end, I started to acknowledge our last session before singing the closing song. In our last session, Mary asked me to sing and play the guitar for her, using hand gestures. When I began to sing You are my Sunshine on the guitar, she moved her right hand slowly and gracefully as if dancing in the air. I acknowledged her hand dance through singing the tune and followed her movements in between playing. After a while, I suggested a few different movements to her, such as waving her hand, waving fingers and shaking. When I demonstrated these movements, Mary responded to my suggestion and imitated my demonstrations. I felt a strong mutuality between Mary and myself because she was using all means available to her to interact with me. Although we are from different backgrounds and 
histories, we were able to build a relationship by sharing each other's music and values. We were able to develop a strong rope of connection from an initially weak, thin string.

We closed our last session by singing Jesus Loves Me together. I sang it on the guitar and Mary vocalised with me. When we sang the chorus, she moved her hand repeatedly in a circular shape between me and her as if saying "yes Jesus loves us". I recognised her sign and followed her by repeating the chorus and singing "yes Jesus loves me, yes Jesus loves you, yes Jesus loves us...” 


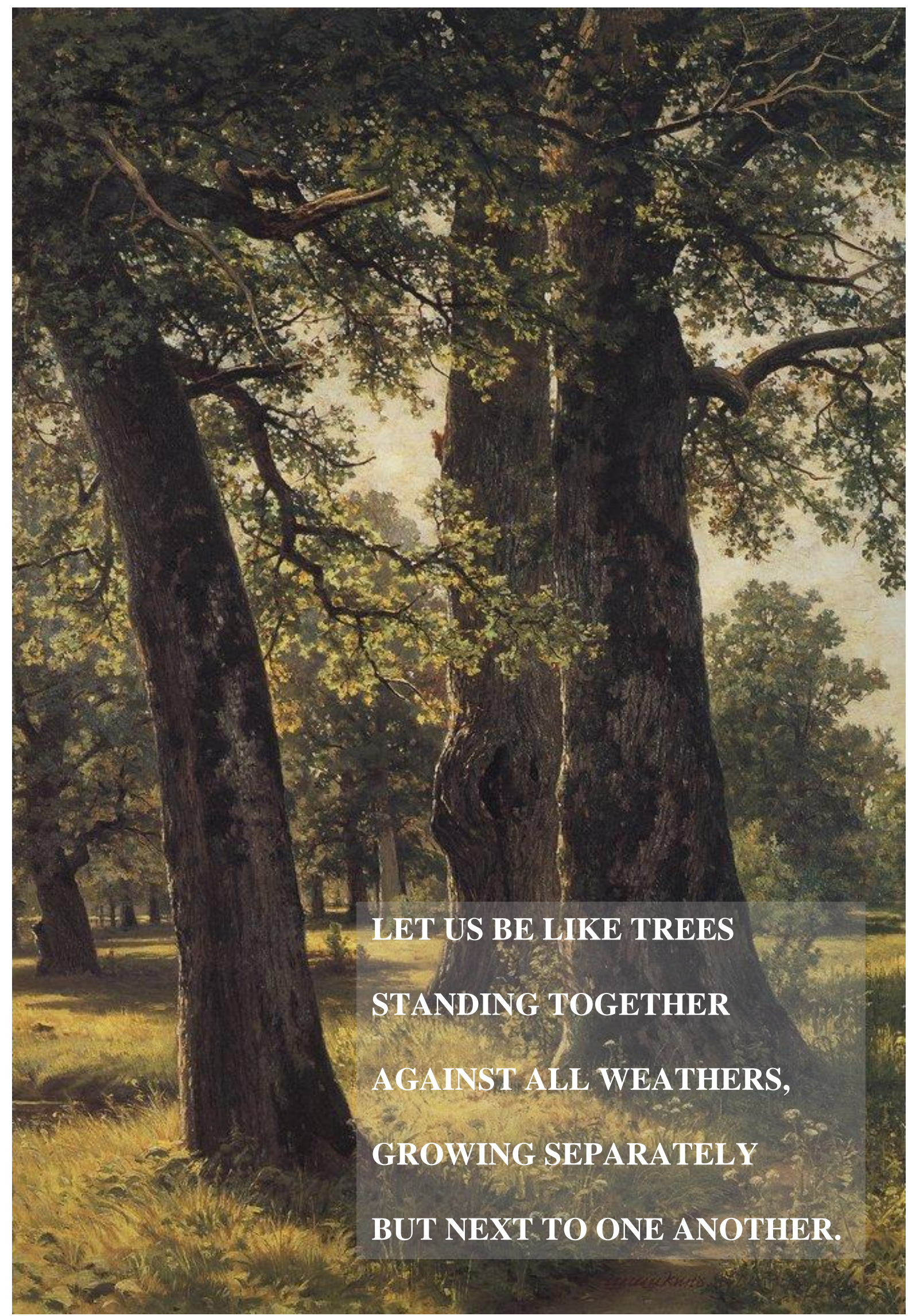

Figure 1. IVAN Shishinin, “OAKs" 1887. QuOtes From Welleran Poltarnees, "AN ANNiversary

BLESSING" 1999. 


\section{Findings}

Let your journey restore your childlike freshness of vision, allowing you to see each new day and place as a revelation.

Delight in the rich variety of ways in which people spend their days... and enjoy the wonderful variety of structures that they live in.

\section{Forget not the infinite variety and beauty of nature's face.}

The use of an heuristic method, if applied in an imaginative and rigorous way, enables the 'essence' of a phenomenon that has been developed from the researcher's critical self-reflections and intensive analysis of data to be explored (Gilroy, 2006). As a result, heuristic research leads to a rich and comprehensive depiction of essential meaning (McLeod, 2011). In this chapter, I will illustrate the main themes and their meanings that emerged from the heuristic process of my experience and through a thematic analysis method. The main findings were my new understandings that: I responded with strong and unusual feelings in my work that related to cultural identities for me and my clients; I looked back to my own and my clients' reactions in sessions and discovered that they were strongly related to my cultural identities, and interpreted that clients' reactions could be also culturally relevant; I made connections and disconnections with clients that appeared, as I interpreted them, to relate to the clients' and my cultures; and I made attempts to learn to adapt and refine the MT methods and skills.

Four main themes were identified through thematic analysis of data:

1. Experiencing strong feelings as an SMT

2. Observing my own reactions as an SMT and interpreting clients' reactions

3. Making connections and disconnections with clients

4. Learning to adapt and refine the use of MT methods 
I tried to illustrate how I understood these four main themes as self-explorative outcomes of actual interactions with MT clients. Interactions were the central linking point for each of the four themes, and is positioned as the trunk of the tree in the diagram below. It occurred to me that self-discovery was possible through an interactive way of working with clients. I will enlarge on this in the discussion section.

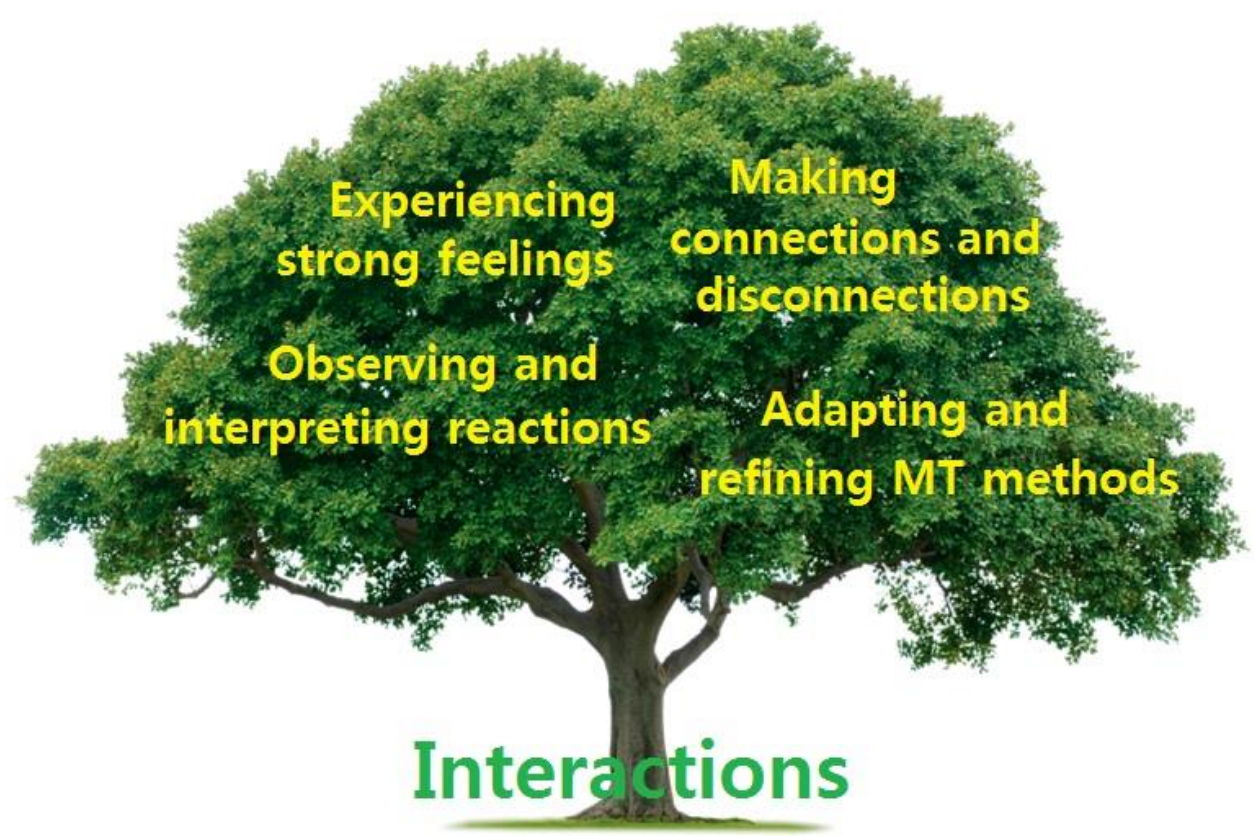

Figure 2. FOUR MAIN THEMES OF THE FINDINGS

A number of sub-themes and categories were revealed in the thematic process. In this section, I present the sub-themes and categories under each main theme, and illustrate each area of discovery with examples from documented experiences with my MT participants. I have had to be selective in this process and have aimed to choose examples from across the range of my placement work that I felt were most resonant or best represented each category. Examples of the sub-themes and categories, with the quotations from my reflexive journal, are presented in Appendix 12. 


\section{Findings from my MT placement in community settings}

\subsection{Experiencing strong feelings as an SMT}

I experienced strong and unusual feelings during my MT placements in community settings at a rest home and two schools. Clinical supervision and my reflexive journal helped me to identify these feelings as strong emotional reactions. I noticed that different feelings were experienced at particular times and situations with certain clients, which I felt related to my cultural experiences. (See Appendix 12, Table 1 for examples of codes)

Different feelings can be experienced when interacting with clients in the moment:

1) I feel limited in my offering

2) I feel connected, close, and intimate with the client

3) I feel culturally accepted by the client

4) I can empathise with the client's particular situation

5) I can be confident in client-led activities

6) I feel familiar and confident with my version

7) I enjoy and have fun making music with the client

I noticed that I was experiencing a complexity of feelings at the time when I was interacting with clients. These feelings were connected to specific cultural and personal experiences. For example, I was able to empathise with the particular situation of a client, where the client was experiencing difficulty in speaking and communicating with others at school, which seemed to be related to social anxiety (Reflexive journal 24/09/14). While observing the client's experience, I was reminded of my own experience of being a teenaged Asian girl in a foreign land. I remembered that it was a big challenge for me to relate with others and express myself, because English was my second language. In this situation, it was evident that my experience as a Korean immigrant enabled me to empathise with my client in the moment of the MT interaction. 
Different feelings can be experienced in specific ways in response to client's reactions and expressions:

1) I can feel uncomfortable with the client's authoritative behaviours

2) I can feel overwhelmed by the client's challenging behaviours

3) I feel guilty when the client withdraws from MT

4) I am not prepared to respond to the client

5) I can feel right/not right about responding to the client

I was interested to find that these feelings were distinguishable from the feelings experienced while interacting with clients in the moment, because these feelings were only experienced when I received particular responses or expressions from clients. For instance, I felt overwhelmed by a young client's challenging behaviour. The client wanted to take one of the school's guitars with him after the session had finished. I tried to negotiate with him but he got very upset and disappointed, and he would not comply (Reflexive journal 02/04/14). My confidence as a student was affected here, especially as it was my first session and getting somebody to help was extra tricky. Also, my lack of confidence came to the forefront and I felt powerless as a student. In another situation, I felt guilty when one of my group clients stopped coming to group session, because I felt that her decision was related to the way I interacted with her (Reflexive journal 26/05/14). Such feelings were very powerful and encouraged me to reflect back on the way I worked as an SMT.

Different feelings can be experienced while preparing for MT sessions:

1) Regretting having the session in an inappropriate space

2) Regretting not being clear with the client and having an unexpected session

3) Getting upset when a session is cancelled without prior notice

4) Feeling uncomfortable with the session time and/or structure

5) Feeling uncertain about presenting cultural material

6) Struggling with a client's contrasting needs

Different feelings were experienced outside of the MT sessions while I was not interacting with clients. The preparation of MT sessions was when my feelings were most expressive and my identities were observable. I experienced a lot of challenges in maintaining a safe and 
appropriate space for MT sessions at one placement. The liaison person recommended that the staff room would be a good space, where there was a piano and room for freer movement. However, when the session began, people kept entering and moving around the room, and I regretted being submissive and not being proactive about my own practice (Reflexive journal 04/06/14). This kind of experience encouraged me to change the way I work and communicate with teachers and others staff. I think this revealed something about both my student role of liaising with staff and the part of my Korean identity involving being submissive and complying with others.

\subsection{Observing my own reactions as an SMT and interpreting clients' reactions}

During the process of data analysis, I was able to observe my characteristic reactions both in various MT situations and to my clients. I often reacted to certain situations or people by reflecting on how I felt about them, and responding proactively, submissively, or naturally to the events or people. The ways I perceived and interpreted the reactions of my clients were also varied. I understood some reactions of clients as proactive when clients expressed their interest and respect for another culture. I saw some other reactions of clients as being natural when clients interacted with their authentic and unpretentious selves. By looking back on my own reactions and making interpretations of my clients', I was able to discover a number of areas of cultural relevance to these observed reactions. (See Appendix 12, Table 2 for examples of codes)

My reflections on experience in MT practice:

1) Clients can surprise, energise, help or confuse me

2) New understandings about the client's culture, personality, family and health/living conditions

3) Discovering new aspects of client

4) New learnings and insights about MT work in general

5) Working with elderly people encourages my cultural self

6) I need to be more proactive 
7) I need to be more sensitive to clients' needs and in understanding their capacities

8) Learning about working in a school environment

I reacted with my student self when I was confronted with new things that I had not yet experienced, such as working at schools with young children with different needs or in a palliative care setting with older adults. Most of my reflections were on the new learnings about clients and MT work. For example, I reflected on the new learnings about a client's culture and personality when the client demonstrated her ways of welcoming another cultural being (Reflexive journal 16/06/14). It was a new and powerful experience as a student. Lack of knowledge of my clients and their culture, and my personal anxiety about new and unfamiliar experiences increased my desire to learn more about my clients and seek different ways of working with them.

My student identity was also activated when I gained new learnings and insights about MT work in general. For example, when I went through complex emotional distress as a result of a sudden end of my MT work with a client who died, I reflected on the meanings and values of the process of relationship (Reflexive journal 04/08/14). Since it was a very strong experience to see a client pass away suddenly, I needed extra support to manage my reactions and to understand the impact of loss for me and others at the placement. As a student, receiving advice during supervision and talking to music therapists were very helpful when reflecting on my MT work.

\section{My proactive reactions as an SMT:}

1) Making suggestions and taking initiatives

2) Taking risks when interacting with clients

3) Trying to understand and learn about clients by thinking from the client's perspective and questioning myself

4) Seeking professional advice

One of the challenges during my MT practicum was to become more proactive and direct in expressing both my student and Korean identities when sharing ways of doing things that 
were new to the people I was working with. During the data analysis, I noticed that I practiced being more proactive and upfront by taking risks when interacting with clients. As an example, I took risks by introducing a Korean version of a client's favourite hymn (Reflexive journal 05/05/14). It provoked a fear of being judged or disregarded before I made the suggestion to the client, but as soon as she accepted my idea and showed her interest, the anxiety disappeared and I began to interact confidently with her. Taking risks and being more proactive in presenting my identities enabled some deeper interactions with clients.

Seeking professional advice was my attempt to become more proactive as an SMT. Because I was new to many MT situations and client groups, I found it extremely valuable to talk to experienced music therapists (Reflexive journal 18/03/14). Also, supervision was a good place for me as an SMT to raise different issues in MT and examine my own attitudes in an objective way (Reflexive journal 01/04/14).

My submissive reactions as an SMT:

1) Being passive

2) Being submissive, can't say no

3) Being careful in "pushing" clients

4) Being careful in responding to clients

As noted earlier, being submissive to and complying with others is part of my Korean identity, as I grew up in a Korean family and have been taught to be obedient, observant and await the advice of adults. For example, I felt very uncomfortable when an older client asked me to sing when it felt inappropriate to do so. I reflected on this as an internal conflict that comes from my Korean heritage, where younger people cannot say no to older people (Reflexive journal 07/04/14). My Asian identity appeared to limit my confidence to be more assertive in MT situations.

As illustrated earlier, examples of myself being proactive show how uncomfortable I felt in taking risks. Sometimes, my submissive self was presented through my student identity too. 
In such circumstances, being submissive and passive came from not knowing enough about the clients or about MT work. For instance, when I started working with registered music therapists in co-therapy sessions, I often tried to stay observant and watch for cues instead of trying to come forward and lead actively (Reflexive journal 10/03/14). Having insufficient knowledge of the clients and MT work concerned me in terms of how to act as a facilitator in the session, and compelled me to be more careful in taking initiatives.

\section{My involuntary reactions towards my clients:}

1) Having fixed perceptions about the client

2) Experiencing a personal struggle with cultural issues of 'age' and 'respect'

3) Being resistant to clients' authoritative behaviour

Some of my reactions towards clients included involuntary and natural reactions that I was not aware of, such as fixed perceptions about clients and personal struggles with cultural issues in MT sessions. A number of entries in my reflexive journal showed that I had a fixed perception about clients when I believed that they would respond positively to a certain type of music. For example, I had an unconscious thought that a client, who had a religious belief, would only respond positively to religious materials (Reflexive journal 09/06/14).

Being resistant to clients' authoritative behaviour was another example of my natural reactions (Reflexive journal 07/04/14). This was very interesting because it seemed to reflect aspects of both my Asian and non-Asian identity ${ }^{2}$, in which I understood our therapeutic relationship to be equal and parallel, while I also felt I needed to comply with an authoritative figure. Such reactions were not planned or decided by myself, but were an immediate emotional response to various situations in MT sessions.

\footnotetext{
${ }^{2}$ This is my new identity that has been created since arriving in New Zealand as 12-year-old.
} 
Proactive reactions of clients:

1) Showing interest in my culture

2) Sharing their own interests with me as an SMT

3) Showing respect to other cultures

4) Being a leader

I interpreted some of the reactions of clients as proactive, because the ways they played and interacted with me during MT sessions felt very willing and prepared. One of the young clients had a special interest in rare and extinct birds and he liked to share it with me (Reflexive journal 18/03/14 and 25/03/14). The topic of rare birds was something very significant to him and he valued it greatly. I could feel not only his enthusiasm for rare birds but also his willingness to exchange his knowledge about it. It appeared as if he was expressing his cultural identity and values. Later on in the session, he shared his specific cultural interest by writing a song.

Clients responded proactively by showing their interest in my ethnic heritage. One of my elderly clients was nonverbal and she often communicated very softly through gestures. But when I asked her if she wanted to hear a Korean version of her favourite song, she responded proactively by nodding promptly and engaging actively in listening to the song (Reflexive journal 05/05/14). Such a response was unusual in sessions with her and I interpreted it as her being proactive although she was not able to talk or move actively.

\section{Client responds naturally:}

1) Expressing a sense of ownership

2) Showing a strong emotional reaction and physical affection

3) Exhibiting transference of own desire

Clients also responded naturally to various MT situations. These responses were distinguishable from proactive responses in the way that the clients responded spontaneously to certain events. One of my clients was Pasifika. When I greeted her in her language, her facial expression changed immediately and she expressed powerful emotions that she had not 
shown me before (Reflexive journal 16/06/14). She was not able to speak due to her specific condition but it felt as if she reacted as who she was to my recognition of her first language. For me as an SMT, it was very unusual and thrilling to observe such a strong and unaffected response, but at the same time I did not know how to respond to her appreciation due to my lack of experience. This experience taught me that receiving a client's genuine responses can be a culturally moving moment.

\subsection{Making connections and disconnections with clients}

I found that I made some significant connections and disconnections with my clients that appeared to be related to both the clients' and my cultural identities. While I am illustrating connections and disconnections separately in this study, from what I have experienced during my MT work, I believe that connections and disconnections exist on the same line across the process of relationship building. That is, connections and disconnections are not limited to time and they can occur at any time and in any circumstances, with or without one's intention. (See Appendix 12, Table 3 for examples of codes)

\section{Connections:}

1) Connection is possible without active verbal communication and can occur through physical and musical interactions

2) Making a connection is related to a sense of mutuality and responsiveness

3) Emotional connections can be formed through "being with"

4) Greeting in a culturally specific way can lead to the making of connections and the appreciation of another culture

During my MT work with elderly and young clients who had specific health conditions that affected their ability to speak, I gained an important understanding that making connections with clients does not always require spoken communication. In fact, making connections is possible through physical and musical interactions. For example, one of my young clients had difficulty in talking to people in spite of his ability to speak. It was not easy to make 
connections with him through spoken language. However, we were able to share a musical conversation as soon as he began to play the harmonica, which enabled me to feel and understand what he was trying to express (Reflexive journal 11/06/14). On the other hand, I felt confident about communicating musically with this client, because my musical self was actively presented. Communicating through music allowed both the client and me to use our intimate identity, in which we could be true to and confident in ourselves.

\section{Disconnections:}

1) Disconnection can take place in different ways; physical, musical, and emotional

2) Endings can be either prepared or unpredictable

3) Language barriers (i.e. client speaking another language, barriers in understanding clients and their culture) and my low confidence in English can challenge the development of the relationship

Similar to the idea of non-verbal connections, disconnections can be of different forms, and emotional disconnection is one type. As a student, I felt insecure when there was an emotional disconnection from clients. Feeling disconnected from the client stimulated anxiety and increased concerns about working with the client. Sometimes, I was not able to find a space in which to be connected to a client and felt that it was only me who was trying to make a connection (Reflexive journal 12/05/14). In such situations, my identity as an SMT was challenged and I felt incompetent and inadequate.

Also, my sense of connectedness was challenged when I felt less confident about being spontaneous with using English in MT work. When I was uncertain about the choice of words or expressions, the way I sang and improvised during the musical interaction was also affected (Reflexive journal 15/04/14). It was evident that my identity as a student was closely related to the sense of connectedness and disconnectedness. 


\subsection{Learning to adapt and refine the use of MT methods}

A number of MT methods were adapted and refined as tools for supporting clients' cultural identities. I tried to acknowledge the client's specific cultural experiences and traditions by writing songs with clients, adapting culturally specific songs into MT sessions, and offering clients with the choices of MT activities. The ways I facilitated MT work were also important indicators of my sensitivity to support the client's cultural needs. (See Appendix 12, Table 4 for examples of codes)

Using MT methods to support a client's cultural identity:

1) Matching and reflecting a client's experience and culture by writing songs about the client's special interest

2) Supporting a client's cultural identity by adapting culturally specific songs

3) Empowering my client's cultural self and sense of control by offering choices of MT activities

There are many different ways to share one's culture and make connections with people.

During my MT work with clients from diverse cultural backgrounds, I found sharing songs particularly effective and moving, especially when connecting with new cultures. Throughout my work with a woman of Pasifika heritage, I learnt a number of songs from my colleagues and another client who were also from the same ethnic heritage. I used one of the well-known songs to create a special closing song for an MT session with this woman. When I used this song for our closing routine, she looked more relaxed and prepared for the ending (Reflexive journal 09/06/14). Such experience taught me that bringing materials that are familiar to a client's culture can be an empathetic and reassuring way to support the client's cultural identity.

Adapting different facilitating skills in MT sessions:

1) Free and thematic improvisations can encourage musical and verbal interactions

2) Offerings music can be useful when initiating interactions

3) Adjusting and choosing appropriate instruments is important when working with 
clients who have reduced physical capacities

4) Finding and keeping the right space for MT is important for protecting the client's safety and maintaining consistency in the relationship

During my MT work with clients who were physically less able due to specific health conditions, I studied different ways of interacting with them as it was not easy for me to understand their means of communication. A young client, who was diagnosed as having muscular dystrophy, enjoyed playing table hand bells in group sessions. She often used them to indicate her choice when we played conducting games. I brought a particular instrument for her, thinking she might be able to press it and make sounds. However, I overestimated her ability to control her power and posture when playing it (Reflexive journal 23/07/14). She played the bells too powerfully and eventually hurt her hands. This changed my perspective on preparing for and facilitating MT sessions with her and it motivated me to become more sensitive in choosing instruments and activities when interacting with her.

\subsection{Summary}

To summarise, I have illustrated the four main findings that represent new discoveries about myself. Before I started my journey, my ethnic identity was the first and most obvious identity that I began with in this process. However, the heuristic process of reflecting on my MT work revealed more about the multiple layers of my identities: being an SMT, a musician, a Korean and a New Zealander. Experiencing strong feelings, looking back at my own reactions and interpreting the clients' reactions, making connections and disconnections, and learning to adapt and refine the use of MT methods were all connected with the multiple identities that I explored through the heuristic process.

At the beginning of this section, I tried to express the sense of partnership and companionship that I have gained from interactions with my clients by presenting a quote by Poltarnees and a painting by Shishkin (Figure 1). I imagined the trees as the individuals, interrelated with each 
other to build relationships. I imagined that each person (tree) has multiple identities and roles that can spread out like branches and leaves, interacting with others and growing together. This idea seemed to be pertinent to the four main areas of the findings, which I interpreted as an essential part of the process of building therapeutic relationships. 


\section{Discussion}

I wish for you to resist the pull of time - to savour each day

and place...

taking the time to explore interesting side streets, climb inviting

staircases and talk to any who have the time to talk to you.

Let the map inspire you, and the road whisper your next destination.

May you daily experience the essential kinship of all people beneath the accidents of culture.

In this heuristic research, I studied my own emotional and cognitive responses as an SMT, and discovered that these responses reflected aspects of my cultural identities. This heuristic process helped me to discover my multiple cultural identities and understand their implications in my MT work with clients from diverse cultural backgrounds. The main and subordinate research questions were:

$>$ How does an SMT's exploration of her cultural identities relate to MT practice in a specialist MT centre in Aotearoa New Zealand?

$>$ How can an awareness of self and exploration of personal cultural identities deepen personal understanding of MT with clients from diverse cultural backgrounds?

In this chapter, I will review the four main themes from the previous chapter and link these to the relevant literature to discuss how the current study connects to earlier MT research. I will also reflect on the processes and limitations of the current study.

\subsection{Review of the Main Findings}

From thematic analysis of the data, I discovered that each area of the main findings reflected different parts of my cultural identities. It was my student identity and roles that were highlighted when confronted with unfamiliar experiences, whereas my Asian identity and Korean-ness were prominent when I connected with other ethnicities. My musical identity 
was highlighted when I shared a deep musical conversation with my clients or when I acted as a facilitator in musical activities.

Being aware of my own feelings and reactions during the course of MT practice helped me to become more sensitive when interpreting the responses of my clients, and therefore encouraged deeper relationship building. I learnt to interpret reactions from me and my clients in a more culturally open-minded way as I went through the practice and research process. From the client's point of view, discovering and interpreting their different reactions made me aware that they have different cultural identities too.

\subsubsection{Multiple identities}

Throughout the research process, it was evident that both my MT practice and I as a person were deeply affected by the different parts of my cultural identities. It was not only my ethnic identity that influenced the way I interacted with my clients, but my student and musical identities also played a significant role in building therapeutic relationships with them.

Ruud (1998) commented that we become ingrained in the culture of the group we are in, and eventually become more aware of our roles in the group. As an SMT, I felt I was embedded in the unique culture of different MT placements (i.e. schools and a rest home), in which I discovered my new roles as a student. As an example, working in a school environment forced me to become more proactive and assertive when communicating with liaison staff in order to protect the safety of my clients and the consistency of therapeutic relationships. At a rest home, I found that I needed to manage my reactions in times of trouble and loss as I learnt the culture of the rest home.

We can also create a new meaning in our existing identity by being part of a social or cultural group (Ruud, 1998). Being a student in MT training created a new meaning in my student 
identity. Being an SMT encouraged me to learn to adapt and refine MT methods and skills in addition to my musicianship and personal characteristics. I have learnt to use my music skills and personality in a therapeutic way, as for example when I adapted a culturally-specific song with a client from the Pasifika culture or when I refined my way of preparing and facilitating MT sessions with clients who are physically less able.

Ethnic identity can be created within the culture of the family. We develop our identity and sense of self during the time we spend with our family, in whom we find our cultural values, beliefs, customs and heritage (Thomas \& Schwarzbaum, 2011). I was brought up in a Korean family and lived with implicit Korean values and beliefs. As noted in the personal relevance section in the first chapter, I grew up around people who believed that respecting one's elders and being modest is a virtue. As a Korean immigrant, I also experienced the challenges of living in a foreign country. Whether I wish to or not, I bring my Korean immigrant identity to my MT work, where I find it both helpful and challenging. For example, I found my immigrant experience useful when I worked with a young client who did not speak because of anxiety and low confidence. I was able to empathise with his situation as I had a similar experience when I was young. On the contrary, I found it very challenging to be more proactive in expressing my needs when I had to speak up for an MT space at a school.

Music transmits the emotions and values of the group we are in, and it can represent who we are and where we belong (Kenny \& Stige, 2002; Gilboa et al., 2009). Therefore, the music that therapists bring to their MT work may reflect a combination of their identity, preferences, life experiences and personal memories (Amir, 2012). As Ruud (1998) pointed out, music therapists need to be aware of their musical identity and understand how music works in MT practice, not only to increase sensitivity to their own culture but also to find the right approach for their clients. During my MT work at a rest home, I used a lot of Korean songs to reflect clients' emotions in my own way or to provide clients with a different 
experience by singing familiar songs in a Korean version. In a school setting, I used my musical identity to interact with young clients through a deep musical conversation. In both cases, I was expressing my 'self' as a person with a Korean heritage and unique life experiences. I expressed my musical self naturally to clients and sometimes with the intention of meeting clients' differing needs.

During the heuristic process of interpreting the client's responses, I realised that they too may have multiple cultural identities in addition to their disability identity. For instance, I was stunned when a client, who could not move freely due to her illness, greeted ${ }^{3}$ me by fully expressing her ethnic values. For her, having a physical illness was not an obstacle to demonstrating her ways of welcoming people and showing her cultural values. I also experienced a client expressing his personal interest, which he valued greatly. By sharing his specific cultural interest in rare and extinct birds with me, the client showed me that he had multiple cultural identities other than his disability identity.

Sometimes, I found it difficult to understand the culture of my client's physical disability, especially when I tried to communicate using musical instruments. When I worked with a young client with muscular dystrophy, I misinterpreted her method of playing the instruments and chose an inappropriate instrument. As Nettles and Balter (2012) commented regarding misconceptions in communicating with Deaf people, I noticed that I was not sensitive enough about my client's different ways of interacting. In fact, clients have their own ways and customs that are unique to them and are effective in practice (Nettles \& Balter, 2012). From this experience, I learnt that thinking from the client's perspective and learning about their ways of interacting are vital for effective communication.

\footnotetext{
${ }^{3}$ The client demonstrated her own ways of welcoming people by shaking and kissing my hand, sharing deep eye-contact, and touching my hand to her chest.
} 


\subsubsection{Interactions with clients}

As I illustrated in the tree diagram in the previous chapter, I feel that the actual MT interactions with clients are the central part of my work, and that all the learnings about my own multiple identities as well as my clients' follow as a result of that. As Gadberry (2014) found during her experience of providing MT in a foreign country, self-discovery can be achieved through meeting and interacting with people.

It was interesting to discover that my interactions with clients in MT allowed me to: experience strong feelings; observe my reactions and interpret my clients' reactions; make connections and disconnections with clients; and learn to adapt and refine MT methods. Working interactively with clients enabled me to reflect and learn about how I understood my own feelings, reactions, and MT practice, and to use different aspects of my cultural identities in my MT practice.

Stige (2002) described a therapist's cultural sensitivity as "openness to the possibility that things may always be different." (p.321). In fact, cultural misunderstanding ${ }^{4}$ can occur when interacting with individuals from diverse cultural backgrounds. Being open to the possibilities for both cultural misunderstandings and opportunities can help us to reduce the cultural gaps in multicultural interaction.

\subsection{Implications for MT Culture and the Community}

Before I started this research, my understanding of 'culture' and 'identity' was restricted to a basic level, where I considered one's culture and identity simply as a reflection of social and ethnic heritage. As I became more aware of the distinctiveness of my feelings and reactions

\footnotetext{
${ }^{4}$ This can be misunderstanding in a disability culture, an ethnic culture, a musical culture or the culture of a specific group or place.
} 
in various cultural settings during my MT practice and research process, I discovered that my understanding of culture and identity has widened to an individual and community level.

The findings of the current study suggest another way of understanding an individual's 'self' as a multiply cultural being. Music therapists and trainees may thus benefit from looking at individuals as unique multicultural beings when they interact and build relationships with their clients (Hadley, 2013b; Brown, 2001).

Considering the role of community is also important in locating and creating an individual's cultural identity. From the community MT perspective, where 'community' is understood as a communion involving a sense of belonging and mutuality (Pavlicevic \& Ansdell, 2004), searching for one's identity is about finding the "balance between being-yourself, being-partof and being-together" (p. 82). That is, a sense of community is important in understanding an individual's sense of self.

Pavlicevic and Ansdell (2004) discussed the individual's self-identity from the socio-cultural perspective. They suggested two directions of understanding one's identity: from individuals to the society, in which an identity is "personally created" and "interpersonally constructed"; and from the society to an individual, where one's identity is "constructed from social structures and cultural materials" (p. 81). Such an approach to understanding identity can raise questions of whether an individual or a society comes first, and where our identities emerge from.

\subsection{Reflections on the Research Process and Limitations}

During the initial stage of the research process, I had unresolved questions and uncertainties about each part of the research process due to the nature of heuristic research. It seemed as if I was travelling around a big city without any maps or signposts to give me directions. 
Because I was using my own experience as the research data to search for its relationship with MT practice, it was essential for me to persist in reflecting upon my reactions as a researcher.

Using reflexivity was very useful during this process, as it enabled me to interrogate my experience in relation to MT work, and gave increased self-awareness of my own reactions as a researcher. Reflexivity was used during the course of data analysis and interpretation of data. I was able to improve my understanding of the possible implications of my role as a researcher on each part of the research process. For instance, I noticed that I was using my personal experience and assumptions as a tool to search for meanings from the data during the process of data analysis and interpretation. Although it is difficult to keep balanced and rigorous in this process, as all the data and thinking is my own, I sought to keep alert to my own 'habits' and limitations in awareness in discussions with my clinical and research supervisors. It was nevertheless exciting to observe the meanings being constructed from my own experience.

I have identified several limitations in this study. First, I had to limit the scope of the research topic and focus on cultural identities, as there are far too many issues to discuss relating to 'culture' and 'identity'. It was not possible to acknowledge and discuss every piece of MT literature on culture and identity. Secondly, I was only able to use the entries from my reflexive journal ${ }^{5}$ for the research data, because I chose to focus on my personal experience to represent the unique multicultural experience in MT practice. Although the journal contained sufficient information for this particular investigation (i.e. materials from the actual MT work with clients and my thoughts about musical interactions and clients' responses), using a wider

\footnotetext{
${ }^{5}$ I kept a reflexive journal during my MT practicum, which contained information gathered from the actual clinical work, observational records, and transcripts of verbal and musical interactions.
} 
range of data sources could have provided a richer outcome, especially when I illustrated examples of specific experiences.

Being a student researcher while practising as an MT clinician was another challenge, in which I occasionally found myself thinking about the research question while I was preparing for MT sessions. However, having such awareness helped me to shift between different roles in different situations, and I sought to minimise any possible changes in my MT practice as a result of the reversed positioning of my roles. Conversely, being a student researcher and learning to use reflexivity in my MT work helped me to gain better understanding about various issues in the therapeutic relationships with my clients.

\subsection{Future Research}

Further study on the issues of therapists' and clients' multiple cultural identities would help to promote professionals' and the community's awareness in this area. As noted earlier, the subject of culture and identity is becoming a critical part of MT practice as the clientele has become more culturally diverse and MT discourse in this field has developed. Also, many MT professionals have emphasised the importance of music therapists' awareness of self and identity. Further research on this subject will contribute to expansion of the research dimensions in this area.

Varied research methods can be employed to study therapists' and clients' cultural identities (Swamy, 2011; Wheeler \& Baker, 2010). Traditional methods might include conducting interviews or surveying therapists and clients, but other culturally specific approaches, artsbased methods, or frameworks from indigenous research methodology (Kenny, 2004) would be particularly appropriate in this field. Applying such methods to a larger number of participants would produce a wider range of data that may improve the representation of cultural diversity. 


\section{Conclusion}

When you return
you will find that you have been given
the ability to see your own land with
freshened perception.

This heuristic research has explored my multiple cultural identities as a Korean woman, an SMT and a musician in relation to my MT work with clients who also have multiple cultural identities. As a result of this heuristic study and the secondary analysis of my own emotional and cognitive responses during MT practice, my experiences and reactions can be grouped as follows: I responded with strong feelings that related to cultural identities for me and my clients; I reflected back on my own and my clients' reactions, in which I found that they were closely related to my cultural identities and interpreted that clients' reactions could also reflect their cultural identities; I made connections and disconnections with my clients; and I learnt to adapt and refine the use of MT methods.

The findings of the research suggest that being aware of their own feelings and reactions can help therapists to become more sensitive when interpreting the responses of their clients, and this may encourage the building of deeper therapeutic relationships. Also, thinking from the client's perspective, learning about their ways of communication and understanding that they also have multiple cultural identities can reduce cultural gaps and widen the therapist's understanding of culture and identity.

The use of reflexivity during the research process contributed to my increased awareness of my own and my clients' multiple cultural identities as a practitioner. I was able to monitor the potential implications of my personal experiences and assumptions on the process of data analysis and interpretation. I was also able to relate my practice and research learning to gain 
knowledge and experience as a new professional. This seemed to be particularly helpful to me as a student completing my MT studies.

To conclude, therapists can experience a range of feelings and reactions when they work with MT clients in an interactive way. However, looking at our different feelings and reactions with a culturally open-minded attitude, we can discover other aspects of our 'selves' and improve our cultural sensitivity when working with clients with diverse cultural identities. Seeing and understanding ourselves as cultural beings, not only ethnically diverse but also individually and aesthetically diverse, can be important in gaining self-knowledge and improving MT practice with culturally diverse clients. 


\section{References}

Aldridge, D. (1995). Spirituality, hope, and music therapy in palliative care. The Arts in Psychotherapy, 22(2), 103-109.

Aldridge, D. (1996). Music therapy research and practice in medicine: From out of the silence. London: Jessica Kingsley Publishers.

Amir, D. (2004). Community music therapy and the challenge of multiculturalism. In M. Pavelicevic, \& G. Ansdell, Community music therapy. London: Jessica Kingsley Publishers.

Amir, D. (2012). "My music is me": Musical Presentation as a way of forming and sharing identity in music therapy group. Nordic Journal of Music Therapy, 21(2), 176-193.

Anthony, W. (1993). Recovery from mental illness: The guiding vision of the mental health system in the 1990's. Psychosocial Rehabilitation Journal, 16(4), 11-23.

Baker, F., \& Krout, R. E. (2011). Collaborative peer lyrics writing during music therapy training: A tool for facilitating students' reflections about clinical practicum experiences. Nordic Journal of Music Therapy, 20(1), 62-89.

Barry, P., \& O’Callaghan, C. (2008). Reflexive journal writing: A tool for music therapy student clinical practice development. Nordic Journal of Music Therapy 17(1), 5566.

Berk, L. E. ( $4^{\text {th }}$ Ed.) (2007). Development through the lifespan. Sydney: Pearson Education, Inc.

Bowtell, E. C., Sawyer, S. M., Aroni, R. A., Green, J. B., \& Duncan, R. E. (2013). "Should I send a condolence card?" Promoting emotional safety in qualitative health research through reflexivity and ethical mindfulness. Qualitative Inquiry, 19(9), 652-663.

Bradt, J. (1997). Ethical issues in multicultural counseling: Implications for the field of music therapy. The Arts in Psychotherapy, 24(2), 137-143.

Braun, V., \& Clarke, V. (2006). Using thematic analysis in psychology. Qualitative Research in Psychology, 3, 77-101.

Brookins, L. M. (1984). The music therapy clinical intern: Performance skills, academic knowledge, personal qualities, and interpersonal skills necessary for a student seeking clinical training. Journal of Music Therapy, 21(4), 193-201.

Brown, J. M. (2001). Towards a culturally centered music therapy practice. Canadian Journal of Music Therapy, 8(1), 11-24.

Christobel, C. M., \& Baker, F. A. (2009). Musical preferences of Argentines and Uruguayans living in Australia: Implications for music therapy clinical practice. Voices: A World Forum for Music Therapy, 9(1). doi:10.15845/voices.v9i1.27

Cominardi, C. (2014). From creative proves to trans-cultural process: Integrating music therapy with arts media in Italian kindergartens: A pilot study. Australian Journal of Music Therapy, 25, 3-14. 
Darrow, A., \& Molloy, D. (1998). Multicultural perspective in music therapy: An examination of the literature, educational curricula, and clinical practice in cultural diverse cities of the United States. Music Therapy Perspectives, 16, 27-32.

Dileo, C., \& Loewy, J. V. (2005). Music therapy at the end of life. Cherry Hill, NJ: Jeffrey Books.

Edwards, J., \& Daveson, B. (2004). Music therapy student supervision: Considering aspects of resistance and parallel processes in the supervisory relationship with students in final clinical placement. The Arts Psychotherapy, 31(2), 67-73.

Epstein, I. (2010). Clinical data-mining: Integrating practice and research. New York: Oxford University Press.

Erikson, E. H. (1968). Identity, youth and crisis. New York: W. W. Norton.

Etherington, K. (2000). Narrative approaches to working with male survivors of sexual abuse: The client's, the counsellor's and the researcher's story. London: Jessica Kingsley Publishers.

Etherington, K. (2004). Becoming a reflexive researcher: Using our selves in research. London: Jessica Kingsley Publishers.

Forrest, L. (2002). Addressing issues of ethnicity and identity in palliative care through music therapy practice. In C. Kenny, \& B. Stige, Contemporary voices in music therapy: Communication, culture, and community. Oslo: Unipub forlag.

Forrest, L. (2014). Your song, my song, our song: Developing music therapy programs for a culturally diverse community in home-based paediatric palliative care. Australian Journal of Music Therapy, 25, 15-27.

Gadberry, L. (2014). Cross-cultural perspective: A thematic analysis of a music therapist's experience providing treatment in a foreign country. Australian Journal of Music Therapy, 25, 66-80.

Gething, L. (1997). Mental illness and psychiatric disability. In L. Gething, Person to person. Sydney: MacLennan \& Petty Pty. Ltd.

Gibson, J. (2006). Disability and clinical competency: An introduction. The California Psychologist, 39, 6-10.

Gilboa, A., Yehuda, N., \& Amir, D. (2009). Let's talk music: A musical-communal project for enhancing communication among students of multi-cultural origin. Nordic Journal of Music Therapy, 18(1), 3-31.

Gilroy, A. (2006). Art therapy, research and evidence-based practice. London: SAGE Publications.

Hadley, S. (2013a). Experiencing race as a music therapist: Personal narratives. Gilsum, NH: Barcelona Publishers.

Hadley, S. (2013b). Dominant narratives: complicity and the need for vigilance in the creative arts therapists. The Arts in Psychotherapy, 40, 373-381. 
Heaton, J. (2004). Reworking qualitative data. London: SAGE Publishers Ltd.

Higgins, R. (1996). Approaches to research: A handbook for those writing a dissertation. London: Jessica Kingsley Publishers.

Johns, E. S. (2013). Sound reflexes: micro-analysis of meaningful moments with children receiving music therapy: An exegesis submitted to Massey University and Victoria University of Wellington in partial fulfilment of the requirements for the degree Master of Music Therapy, the New Zealand School of Music / Elizabeth Scott Johns. 2013.

Kenny, C., \& Stige, B. (2002). Contemporary voices in music therapy: Communication, culture, and community. Oslo: Unipub forlag.

Kenny, C. (2004). A holistic framework for aboriginal policy research. Ottawa, Ontario Canada: Status of Women Canada. Unpublished manuscript, Ottawa, Ontario, Canada.

Kim, S. (2013). Re-discovering voice: Korean immigrant women in group music therapy. The Arts in Psychotherapy, 40, 428-435.

Leigh, I. W. (2011). Not just Deaf: Multiple intersections. In R. Nettles \& R. Balter (Eds.), Multiple minority identities: Applications for practice, research, and training. New York: Springer Publishing Company.

Lichtman, M. ( $3^{\text {rd }}$ Ed.) (2013). Qualitative research in education: A user's guide. London: SAGE Publishers Ltd.

Maat, M. B. (2011). Developing and assessing multicultural competence with a focus on culture and ethnicity. Art Therapy: Journal of the American Art Therapy Association, 28(1), 4-10.

Massey University (2010). Code of ethical conduct for research, teaching and evaluations involving human participants. Palmerston North: Massey University.

McClain, F. J. (1993). Student evaluation of practicum training in music therapy. Dissertation Abstracts International, 54(07), 2502A. (University Microfilms No.DA9332828).

McLeod, J. (2 ${ }^{\text {nd }}$ Ed.) (2011). Qualitative research in counselling and psychotherapy. London: SAGE Publishers Ltd.

Moustakas, C. E. (1990). Heuristic research: Design, methodology, and applications. London: SAGE Publications.

Nettle, R., \& Balter, R. (2012). Multiple minority identities: Applications for practice, research, and training. New York: Springer Publishing Company, LLC.

New Zealand Society for Music Therapy, (2012). Code of Ethics for the Practice of Music Therapy in New Zealand.

Pavlicevic, M., \& Ansdell, G. (2004). Community music therapy. London: Jessica Kingsley Publishers. 
Poltarnees, W. (1999). An anniversary blessing. Washington: Laughing Elephant Books.

Poltarnees, W. (2000). A travel blessing. Washington: Laughing Elephant Books.

Rickson, D. (2010). More thoughts about identity. Voices Resources. Retrieved March 17, 2014, from http://testvoices.uib.no/community/?q=colrickson080210

Ruud, E. (1998). Music therapy: Improvisation, communication, and culture. Gilsum, NH: Barcelona Publishers.

Schwandt, T. A. ( $3^{\text {rd }}$ Ed.) (2007). The SAGE dictionary of qualitative inquiry. Los Angeles: SAGE Publications.

Sela-Smith, S. (2002). Heuristic research: A review and critique of Moustaka's method. Journal of Humanistic Psychology, 42, 53-88.

Smeijsters, H. (1997). Multiple perspectives: A guide to qualitative research in music therapy. Gillsum NH: Barcelona Publishers.

Smiler, K., \& McKee, R. (2007). Perceptions of Māori Deaf identity in New Zealand. Journal of Deaf Studies and Deaf Education, 12(1), 93-111.

Stige, B. (2002). Culture-centered music therapy. Gilsum, NH: Barcelona Publishers.

Sue, D. W., \& Sue, D. ( $5^{\text {th }}$ Ed.) (2008) Counseling the culturally diverse: Theory and practice. New Jersey: John Wiley \& Sons, Inc.

Sullivan, W. P. (1994). A long and winding road: The process of recovery from severe mental illness. Innovations and Research, 3(3), 19-27.

Swamy, S. (2011). Temple of ancient knowing: Music therapy portraits of globalized Indian identity: A dissertation study. (Doctoral dissertation). Lesley University, Massachusetts. Retrieved from Massey University Database. (UMI:3561400).

Tesch, R. (1990). Qualitative research: analysis types and software tools. New York: Falmer Press.

Thomas, A. J., \& Schwarzbaum, S. E. (2 ${ }^{\text {nd }}$ Ed.) (2011). Culture and identity: Life stories for counselors and therapists. London: SAGE Publications, Inc.

Uehara, A. (1986). The nature of American student re-entry adjustment and perceptions of the sojourn experience. International Journal of Intercultural Relations, 10, 415438.

Wheeler, B. L. (2002). Experiences and concerns of students during music therapy practica. Journal of Music Therapy, 39(4), 274-304.

Wheeler, B. L. (2005). Music therapy research. Gilsum, NH: Barcelona Publishers.

Wheeler, B. L., \& Baker, F. A. (2010). Influences of music therapists' worldviews on work in different countries. The Arts in Psychotherapy, 37, 215-227. 


\section{Appendices}

\section{Appendix $1 \quad$ Facility information sheet}

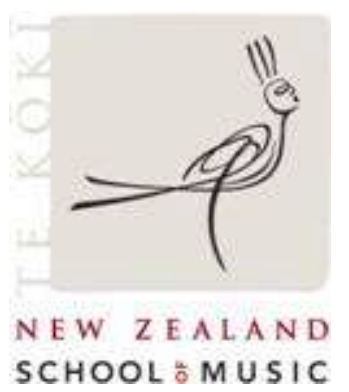

Music Therapy Dept., New Zealand School of Music, PO Box 2332, Wellington, NZ Tel: 04 463-5233 ext: 35807/35808

To ...

I am in my second year of Masters of Music Therapy degree, and as part of the programme I am required to conduct research relating to the clinical work by using secondary review of data. I have titled my research as "A student music therapist's journey of exploring her cultural identities in relation to music therapy practice in a specialist music therapy centre in Aotearoa New Zealand". This project has been reviewed and approved by the NZSM Postgraduate Committee. I have attached a research proposal for further information about my research.

I would like to ask you for a written permission for the research to take place in ... Please feel free to discuss with me about my research and/or giving permission to conduct research. If you feel you have obtained sufficient information about this research and happy to give permission, please sign the enclosed consent form. Please contact me or my research supervisor Sarah Hoskyns if you have any concerns or questions relating to this research.

Yours sincerely,

Hee-Hyun Han (Student Music Therapist) 


\section{Appendix 2 Facility consent form}

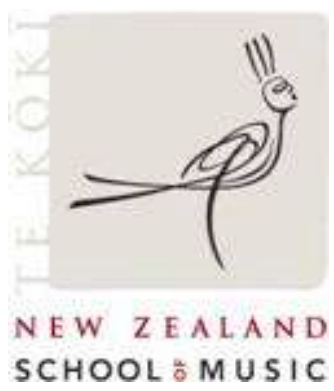

Music Therapy Dept., New Zealand School of Music, PO Box 2332, Wellington, NZ Tel: 04 463-5233 ext: $35807 / 35808$

Research Title: "A student music therapist's journey of exploring her cultural identities in relation to music therapy practice in a specialist music therapy centre in Aotearoa New Zealand"

I,

(name and position), have read information sheet and have obtained sufficient information about the study. I understand that I can contact the student music therapist's research supervisor, Sarah Hoskyns, if I have any concerns or questions relating to the research.

I agree to give permission to Hee-Hyun Han to use clinical records, including written records and audio-visual records kept at..., to develop into the secondary data for research purpose.

Signature

Date

Print name 


\section{Appendix 3 Information sheet for client's caregiver or family member}

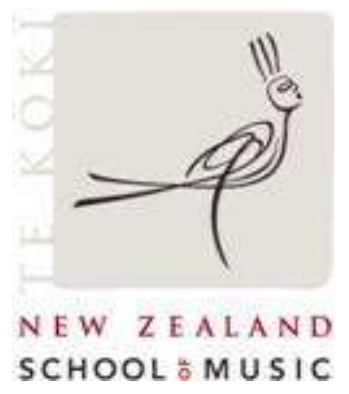

Music Therapy Dept., New Zealand School of Music, PO Box 2332, Wellington, NZ Tel: 04 463-5233 ext: $35807 / 35808$

\section{Research Title: A student music therapist's journey of exploring her cultural identities in relation to music therapy practice in a specialist music therapy centre in Aotearoa New Zealand.}

\section{Information Sheet}

Kia ora,

My name is Hee-Hyun Han, and I am the music therapy student working with ... at .... I am currently on placement at ... as a second year music therapy student. This is my second and final year as part of a Masters of Music Therapy degree at Massey University, Wellington.

I am required to research about music therapy as part of my training. For my research topic I have chosen to explore my own cultural identities in relation to music therapy work, because of my wish to develop cultural sensitivity and curiosity when working with people from different cultural backgrounds. As a result of this project, I hope to increase self-awareness and gain more understanding about the worldviews and cultural experiences of people whom I work with.

My research process will involve recording my own reflections and thoughts about music therapy work with... in my personal research journal and looking back at these records (secondary review) to find relationships between my own cultural identities and the music therapy work. I will be writing a paper about my research, and there will be a section called a case vignette which will describe a particular point of music therapy session with... This is to illustrate any musical experiences or meaningful interactions that are relevant to my research topic.

I would like to ask you to give a written permission for some materials recorded in my personal research journal to be included in this research. These information contains specific musical and personal experiences with... during music therapy sessions. I would also like to use some music therapy session notes to include in a case vignette as part of the research write-up. 
I will not use names or other information that can potentially identify... in any publication or presentation of this research. All the records and consent forms for this research will be stored in a locked cupboard and kept for ten years at New Zealand School of Music. These materials are different to the records of music therapy sessions with... which will be stored at RMTC up to ten years. However there is a possibility for... of being recognised as it is the only music therapy facility in Aotearoa New Zealand. I will make every attempt to protect ...'s privacy and confidentiality.

I will provide a summary of the results of the study to you if you wish to see the findings of this project, but please note that this study may not be ready for publication until early 2015. I will be happy to discuss with you about this study during and/or after the study.

This study has been reviewed and approved by the New Zealand School of Music Postgraduate Committee. The Human Ethics and Health and Disability Committee has given generic approval for me to carry out this project and they have considered it to be low risk.

Please feel free to discuss with me about my research and/or giving permission to use the music therapy materials in the research. If you feel you have obtained sufficient information about this research and happy to give permission, please sign the enclosed consent form. There will be no changes to the ongoing music therapy even if you decide not to give your permission. Please contact me or my research supervisor Dr Sarah Hoskyns ... if you have any concerns or questions relating to this research.

Yours sincerely,

Hee-Hyun Han

Student Music Therapist 


\section{Appendix 4 Consent form for client's caregiver or family member}

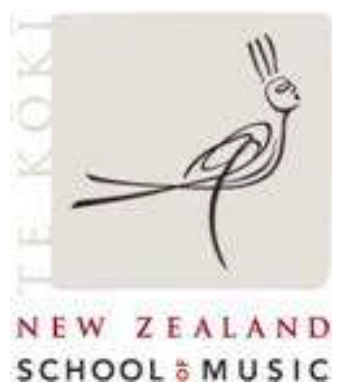

Music Therapy Dept., New Zealand School of Music, PO Box 2332, Wellington, NZ Tel: 04 463-5233 ext: $35807 / 35808$

Research Title: “A student music therapist's journey of exploring her cultural identities in relation to music therapy practice in a specialist music therapy centre in Aotearoa New Zealand"

\section{Caregiver's Consent Form}

- I have read the information sheet and have obtained sufficient information about the study

- I understand that my family member's name will be changed and that the location and name of the setting will not be identified

- I also understand that the research data will be kept in a locked cupboard at the New Zealand School of Music for a period of 10 years

- I acknowledge that the study will be published in the libraries at Massey and Victoria Universities and may be presented in a conference or published paper

- I understand that I can contact the student music therapist and her research supervisor Dr Sarah Hoskyns if I have any concerns or questions relating to the research.

I therefore give consent for materials recorded in music therapy student's personal journal that are related to my family member's music therapy to be developed into the secondary data for research purpose.

Signature:

Date:

(Caregiver/s)

Full name/s printed: 


\section{Appendix $5 \quad$ Information sheet and assent for client}

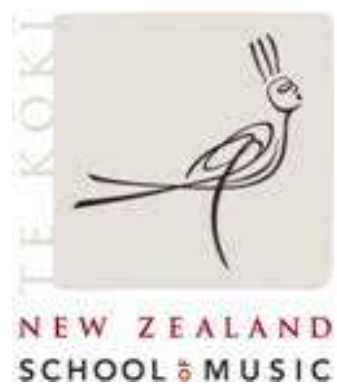

Music Therapy Dept., New Zealand School of Music, PO Box 2332, Wellington, NZ Tel: 04 463-5233 ext: $35807 / 35808$

\section{Client Information and Consent Form}

Hello ...

As you probably know, my name is Hee-Hyun Han and I am a student music therapist. I like to do all kinds of music with people from different culture and places. As part of my study, I am going to write a story about doing music with people from different culture.

I would like to write a story about what we did together during the music time, because I am very interested in what we share when we play together in the music. If it is ok with you, I would like to write about the music things we did together. The story will not have your real name in it.

When I finish writing my story I will give it to ... and ... so they can tell you about it.

If you want to be in my story please say yes by giving a nod, and someone will help you to write your name and date by the smiley face.

Best wishes,

Hee-Hyun Han

Student Music Therapist

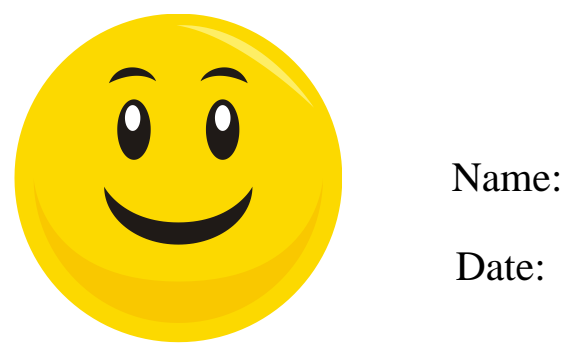




\section{Appendix 6 Information sheet for music therapy clinical supervisor}

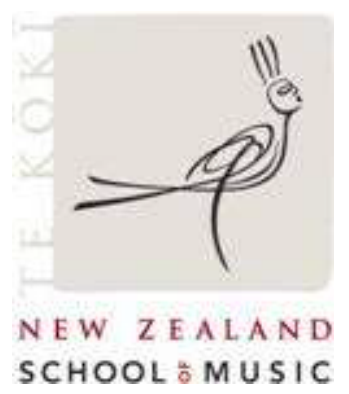

Music Therapy Dept., New Zealand School of Music, PO Box 2332, Wellington, NZ Tel: 04 463-5233 ext: 35807/35808

To ...

As you know, I am in my second year of Masters of Music Therapy degree, and as part of the programme I am required to conduct research relating to the clinical work by using secondary review of data. I have titled my research as "A student music therapist's journey of exploring her cultural identities in relation to music therapy practice in a specialist music therapy centre in Aotearoa New Zealand". This project has been reviewed and approved by the NZSM Postgraduate Committee. I have attached a research proposal for further information about my research.

I have found some of the materials in our clinical supervision came up during the research process especially during the reflexive process, in which I reflect back on some of the topics and issues we discussed together in the supervision meetings. I really value what we share in the supervision because they help me to think and learn more about different aspects of clinical work. They also help me to develop internal supervision skills, which I think is strongly related to my research topic. It would be helpful if I could include some of the materials that I reflected based on our clinical supervision in my research. The materials will be mostly drawn from the entries in my reflexive note.

I would like to ask you for a written permission for some of the materials from our supervisions to be included in this project. Please feel free to discuss with me about my research and/or giving permission to use supervision materials in the research. If you feel you have obtained sufficient information about this research and happy to give permission, please sign the enclosed consent form. Please contact me or my research supervisor Sarah Hoskyns if you have any concerns or questions relating to this research.

Yours sincerely,

Hee-Hyun Han (Student music therapist) 


\section{Appendix 7 Consent form for music therapy clinical supervisor}

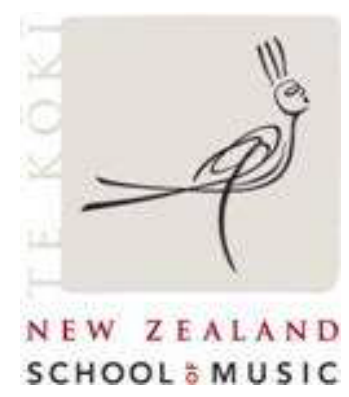

Music Therapy Dept., New Zealand School of Music, PO Box 2332, Wellington, NZ Tel: 04 463-5233 ext: $35807 / 35808$

Research Title: “A student music therapist's journey of exploring her cultural identities in relation to music therapy practice in a specialist music therapy centre in Aotearoa New Zealand"

$\mathrm{I}$, (name and position), have read information sheet and have obtained sufficient information about the study. I understand that I can contact the student music therapist's research supervisor, Sarah Hoskyns, if I have any concerns or questions relating to the research.

I agree to give permission to Hee-Hyun Han to use materials from the clinical supervision, to develop into the secondary data for research purpose.

Signature

Date

Print name 


\section{Appendix 8 Examples of reflexive journal entries}

$09 / 06 / 14$

... rest home

Individual session at $11.15 \mathrm{am}$

... is a religious woman and I used to sing a lot of hymns with her. She would usually respond positively to the hymns. But it was very different today. When I sang Jesus Loves Me, ... suddenly changed her face which made her look angry. She frowned and did not open her eyes or look at me. It was very unusual and unexpected. I stopped singing but continued playing on the guitar, and then noticed that her face came back to her normal state.

I thought I might introduce her a new song, which wasn't part of my plan. I sang the Summertime, a non-religious music. ... listened to the song with her eyes open. She did not seem to be irritated by my song choice. Then I improvised on the song and tried to reflect her mood. She looked calm and peaceful except her breathing was still rough.

I never thought that I would use non-religious songs, because all her files said she responded best to the hymns, and her previous music therapist also commented in her session note that ... loves to listen to the hymns. That's why I avoided using other songs. I still don't understand why she responded negatively to the hymns that we used to sing, but one thing I've learnt is that she can respond positively to other music too! 


\section{Appendix 9 Examples of secondary data analysis (coding)}

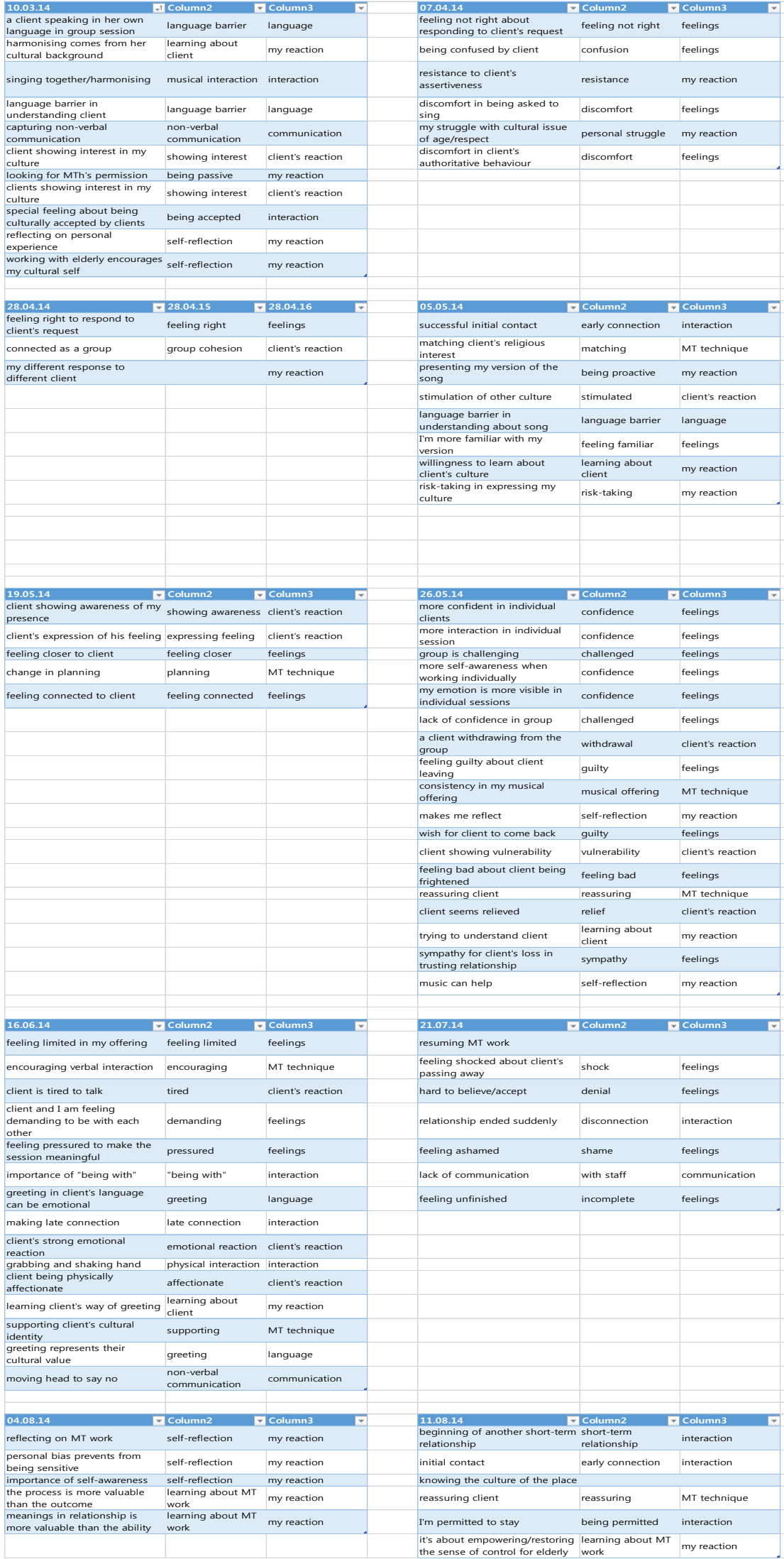

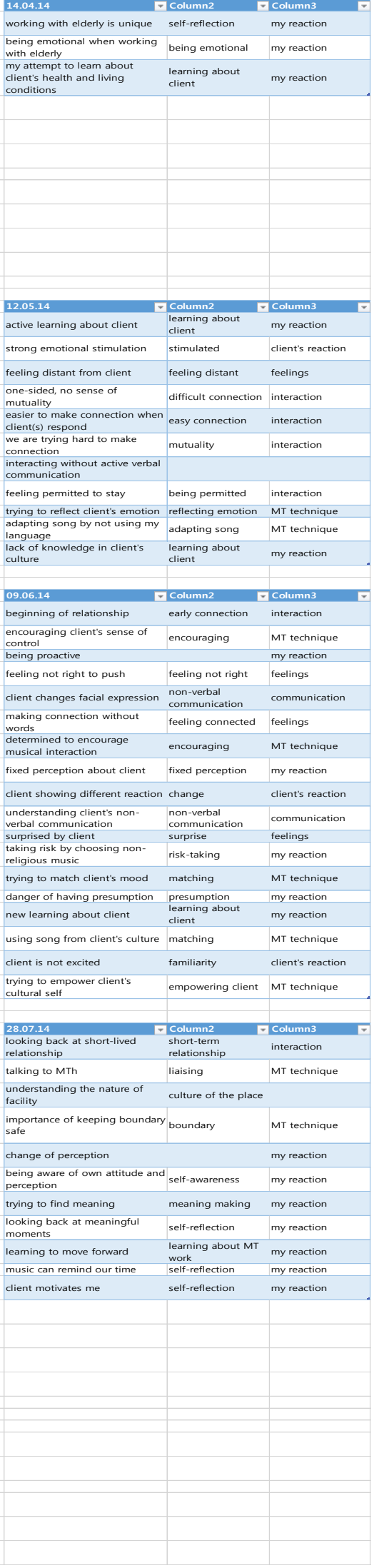




\section{Appendix 10 Examples of secondary data analysis (initial categories)}
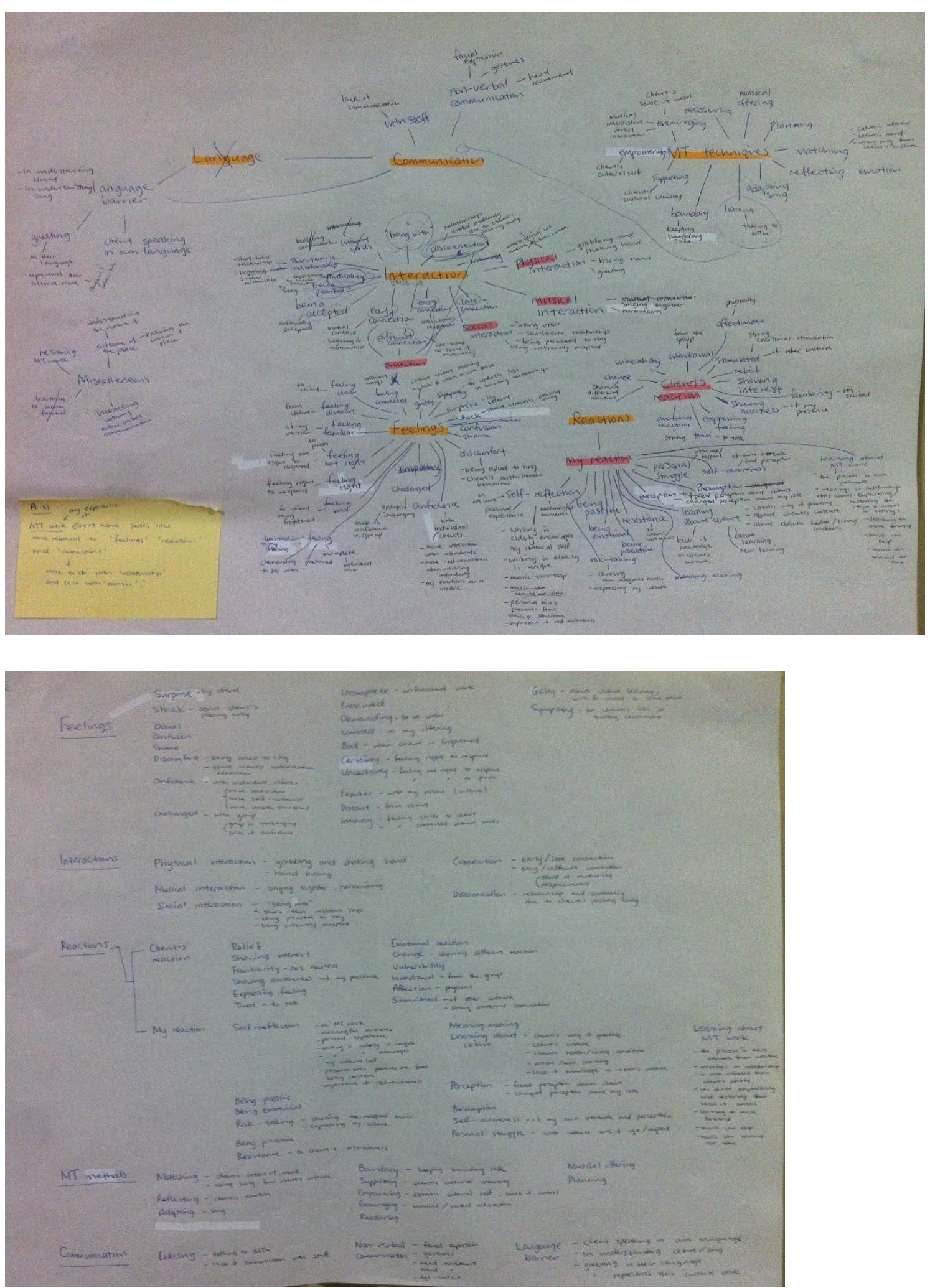


\section{Appendix 11 Examples of secondary data analysis (possible themes)}

\begin{tabular}{|c|c|c|c|}
\hline \multirow{15}{*}{ 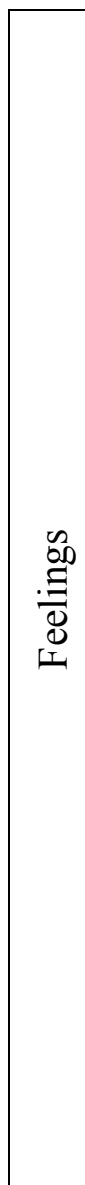 } & \multirow[t]{6}{*}{ Positive feelings } & \multirow{6}{*}{$\begin{array}{l}\text { Surprise, } \\
\text { confidence, } \\
\text { certainty, familiar, } \\
\text { intimacy, } \\
\text { sympathy }\end{array}$} & Surprised by client \\
\hline & & & Confident with individual clients \\
\hline & & & Certainty - feeling right to respond \\
\hline & & & Familiar with my version \\
\hline & & & $\begin{array}{l}\text { Intimacy - feeling closer to client, } \\
\text { feeling connected without words }\end{array}$ \\
\hline & & & $\begin{array}{l}\text { Sympathy for client's loss in trusting } \\
\text { relationship }\end{array}$ \\
\hline & \multirow[t]{4}{*}{ Negative feelings } & \multirow{4}{*}{$\begin{array}{l}\text { Shock, denial, } \\
\text { confusion, shame, } \\
\text { bad, distant, guilty }\end{array}$} & $\begin{array}{l}\text { Shock about client's sudden passing } \\
\text { away }\end{array}$ \\
\hline & & & $\begin{array}{l}\text { Feeling bad when client is } \\
\text { frightened }\end{array}$ \\
\hline & & & Feeling distant from client \\
\hline & & & $\begin{array}{l}\text { Feeling guilty about client } \\
\text { withdrawing }\end{array}$ \\
\hline & \multirow[t]{5}{*}{$\begin{array}{l}\text { Challenging } \\
\text { feelings }\end{array}$} & \multirow{5}{*}{$\begin{array}{l}\text { Discomfort, } \\
\text { unfinished, } \\
\text { pressured, } \\
\text { demanding, } \\
\text { limited, } \\
\text { uncertainty }\end{array}$} & $\begin{array}{l}\text { Discomfort with being asked to sing; } \\
\text { about client's authoritative } \\
\text { behaviour }\end{array}$ \\
\hline & & & $\begin{array}{l}\text { Feeling unfinished with } \\
\text { work/relationship }\end{array}$ \\
\hline & & & Demanding to be with client \\
\hline & & & Feeling limited in my offering \\
\hline & & & $\begin{array}{l}\text { Uncertainty - feeling not right to } \\
\text { respond/ to push }\end{array}$ \\
\hline \multirow{6}{*}{ 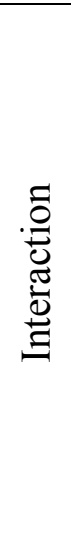 } & $\begin{array}{l}\text { Physical } \\
\text { interaction }\end{array}$ & \multicolumn{2}{|c|}{ Grabbing/shaking hand, kissing on hand } \\
\hline & $\begin{array}{l}\text { Musical } \\
\text { interaction }\end{array}$ & \multicolumn{2}{|c|}{ Singing together, harmonising } \\
\hline & Social interaction & \multicolumn{2}{|c|}{$\begin{array}{l}\text { "being with", short-term relationship, being permitted to } \\
\text { stay, being culturally accepted }\end{array}$} \\
\hline & Connection & $\begin{array}{l}\text { Early/late } \\
\text { connection }\end{array}$ & $\begin{array}{l}\text { Initial contact, beginning of } \\
\text { relationship }\end{array}$ \\
\hline & & $\begin{array}{l}\text { Easy/difficult } \\
\text { connection }\end{array}$ & $\begin{array}{l}\text { related to sense of mutuality, } \\
\text { responsiveness }\end{array}$ \\
\hline & Disconnection & Relationship ended & uddenly due to client's passing away \\
\hline \multirow{6}{*}{ 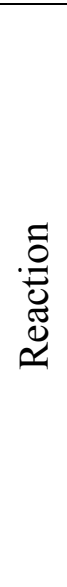 } & \multirow[t]{3}{*}{ Client's reaction } & Positive reaction & $\begin{array}{l}\text { Relief, showing interest, familiarity, } \\
\text { showing awareness of my presence, } \\
\text { expressing feeling, change in } \\
\text { reaction, stimulation }\end{array}$ \\
\hline & & Negative reaction & $\begin{array}{l}\text { Feeling tired to talk, vulnerability, } \\
\text { withdrawal }\end{array}$ \\
\hline & & $\begin{array}{l}\text { Challenging } \\
\text { reaction }\end{array}$ & $\begin{array}{l}\text { strong emotional reaction, physical } \\
\text { affection }\end{array}$ \\
\hline & \multirow[t]{3}{*}{ My reaction } & \multirow[t]{3}{*}{ Self-reflection } & Personal experience \\
\hline & & & Working with elderly is unique \\
\hline & & & $\begin{array}{l}\text { Working with elderly encourages my } \\
\text { cultural self }\end{array}$ \\
\hline
\end{tabular}




\begin{tabular}{|c|c|c|c|}
\hline & & & $\begin{array}{l}\text { Personal bias prevents me from } \\
\text { being sensitive }\end{array}$ \\
\hline & & & Importance of self-awareness \\
\hline & & & Meaningful moments \\
\hline & & & On MT work \\
\hline & & Being passive & \\
\hline & & Being emotional & Expressing my cultural self \\
\hline & & Risk-taking & Choosing non-religious music \\
\hline & & & To client's assertiveness \\
\hline & & Being proactive & \\
\hline & & Resistance & \\
\hline & & Meaning making & \\
\hline & & Learning about & Client's health/living conditions \\
\hline & & client & Active/new learning \\
\hline & & & $\begin{array}{l}\text { Lack of knowledge in client's } \\
\text { culture }\end{array}$ \\
\hline & & & Client's culture \\
\hline & & & Client's way of greeting \\
\hline & & Perception & Changed perception about my role \\
\hline & & & Fixed perception about client \\
\hline & & Presumption & \\
\hline & & Self-awareness & Of my own attitude/perception \\
\hline & & Personal struggle & With cultural issue of age/respect \\
\hline & & $\begin{array}{l}\text { Learning about } \\
\text { MT work }\end{array}$ & $\begin{array}{l}\text { It's about empowering and restoring } \\
\text { their sense of control }\end{array}$ \\
\hline & & & Learning to move forward \\
\hline & & & Music can help \\
\hline & & & Music can remind our time \\
\hline & & & $\begin{array}{l}\text { Meanings in relationship is more } \\
\text { valuable than the client's ability }\end{array}$ \\
\hline & & & $\begin{array}{l}\text { The process is more valuable than } \\
\text { the outcome }\end{array}$ \\
\hline & Matching & Client's interest, $\mathrm{n}$ & \\
\hline & & Using songs from & ent's culture \\
\hline & Reflecting & Client's emotion & \\
\hline s & Adapting & Songs & \\
\hline$\stackrel{\mathscr{\Xi}}{\Xi}$ & Boundary & Keeping boundary & \\
\hline$\widehat{\partial}$ & Supporting & Client's cultural id & tity \\
\hline$\overline{\frac{\pi}{0}}$ & Empowering & Client's cultural se & \\
\hline 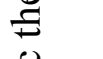 & & Client's sense of c & trol \\
\hline$\cdot \frac{0}{2}$ & Encouraging & Musical/verbal int & iction \\
\hline$\sum^{2}$ & Reassuring & & \\
\hline & Musical offering & & \\
\hline & Planning & & \\
\hline & Liaising & Talking to music t & apist \\
\hline 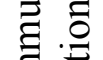 & & Lack of communic & ion with staff \\
\hline हี ت్ల్ల & Non-verbal & Facial expression & \\
\hline & communication & Gestures & \\
\hline
\end{tabular}




\begin{tabular}{|l|l|l|}
\hline \multirow{4}{*}{ Language barrier } & Head/hand movements \\
\cline { 3 - 3 } & Eye-contact \\
\hline & Client speaking in own language \\
\cline { 3 - 3 } & Barrier in understanding client \\
\cline { 3 - 3 } & Barriers in understanding songs \\
\cline { 3 - 3 } & Greeting in their language \\
& Greeting in their language represents their cultural value \\
\hline
\end{tabular}




\section{Appendix 12 Main findings}

Table 1.

Experiencing strong feelings as an SMT

\begin{tabular}{|c|c|c|}
\hline \multicolumn{3}{|c|}{ Experiencing strong feeling as an SMT } \\
\hline \multicolumn{2}{|c|}{ Findings } & Quotations from reflexive journal \\
\hline \multirow{8}{*}{$\begin{array}{c}\text { Different } \\
\text { feelings can } \\
\text { be } \\
\text { experienced } \\
\text { when } \\
\text { interacting } \\
\text { with clients in } \\
\text { the moment }\end{array}$} & $\begin{array}{l}\text { I feel limited in } \\
\text { my offering }\end{array}$ & $\begin{array}{l}\text { I felt like there were not much things I could do } \\
\text { but just playing and singing a few old songs. } \\
16 / 06 / 14\end{array}$ \\
\hline & $\begin{array}{l}\text { I feel connected } \\
\text { with the client }\end{array}$ & $\begin{array}{l}\text { It was the first time he spoke to me and I felt } \\
\text { like I'm a bit closer to him now... It seemed as } \\
\text { if a bridge has begun to form between me and } \\
\text { (client). 19/05/14 }\end{array}$ \\
\hline & $\begin{array}{l}\text { I feel close and } \\
\text { intimate with the } \\
\text { client }\end{array}$ & $\begin{array}{l}\text { It almost felt like one of those 'catch-up' with } \\
\text { your friends... it actually felt like we knew } \\
\text { each other really well over a long time. } \\
22 / 07 / 14\end{array}$ \\
\hline & $\begin{array}{l}\text { I feel culturally } \\
\text { accepted by the } \\
\text { client }\end{array}$ & $\begin{array}{l}\text { When I sing Arirang, people try to listen } \\
\text { carefully and hum along. This feels very } \\
\text { strange and grateful. The feeling of being } \\
\text { culturally accepted and valued is so special... } \\
10 / 03 / 14\end{array}$ \\
\hline & $\begin{array}{l}\text { I can empathise } \\
\text { with the client's } \\
\text { particular } \\
\text { situation }\end{array}$ & $\begin{array}{l}\text { Personally, there were a lot of flashbacks of my } \\
\text { teenage life - how difficult it was to voice up } \\
\text { when it's your second language and when all } \\
\text { other's attention falls on you. Then it was not } \\
\text { strange for (client) to become anxious at school } \\
\text { where it's all about presenting yourself and } \\
\text { relating with people. } 24 / 09 / 14\end{array}$ \\
\hline & $\begin{array}{l}\text { I can be confident } \\
\text { in client-led } \\
\text { activities }\end{array}$ & $\begin{array}{l}\text { I feel like we have made some progress, and } \\
\text { talking for a long time (by client) seems find } \\
\text { between us. } 25 / 03 / 14\end{array}$ \\
\hline & $\begin{array}{l}\text { I feel familiar and } \\
\text { confident with my } \\
\text { version }\end{array}$ & $\begin{array}{l}\text { I know many Korean hymns but very few in } \\
\text { English. I felt confident when I sang the } \\
\text { Korean version of that song although I knew it } \\
\text { English. } 05 / 05 / 14\end{array}$ \\
\hline & $\begin{array}{l}\text { I enjoy and have } \\
\text { fun making music } \\
\text { with the client }\end{array}$ & $\begin{array}{l}\text { I felt that (client) was gradually becoming more } \\
\text { confident in making music, and I noticed that I } \\
\text { felt less self-conscious... I really felt that the } \\
\text { session was going in the flow and that (client) } \\
\text { and I was actually having fun. } 01 / 04 / 14\end{array}$ \\
\hline \multirow{2}{*}{$\begin{array}{l}\text { Different } \\
\text { feelings can } \\
\text { be } \\
\text { experienced } \\
\text { in specific } \\
\text { ways in } \\
\text { response to }\end{array}$} & $\begin{array}{l}\text { I can feel } \\
\text { uncomfortable } \\
\text { with the client's } \\
\text { authoritative } \\
\text { behaviours }\end{array}$ & $\begin{array}{l}\text { I feel uncomfortable when (client) insists me to } \\
\text { sing. She is a very nice woman and I know she } \\
\text { didn't mean to do that, but I often get the } \\
\text { feeling that she's being authoritative and } \\
\text { assertive. } 07 / 04 / 14\end{array}$ \\
\hline & $\begin{array}{l}\text { I can feel } \\
\text { overwhelmed by }\end{array}$ & $\begin{array}{l}\text { (Client) got really upset and disappointed, and } \\
\text { he wouldn't leave the room... I had to take }\end{array}$ \\
\hline
\end{tabular}




\begin{tabular}{cl}
\hline client's & the client's \\
reactions and & challenging \\
expressions & behaviours
\end{tabular}

(client) to one of the TAs and then we were able to send (client) back to the class... it was just so overwhelming given that it was our first session. 02/04/14

Second time in a group session with three boys - absolutely chaotic. It feels like there are three different worlds existing in the same space... Can we really exist together in the same space?... When the group plays "boys game" I feel a bit isolated and left out... All I could do is just to accompany their playing on the guitar - playing Em and Am powerfully as if telling them "I'm here and I want to join!" Then they would include me in the battle field... So, I'm really trying to be with them... but I'm physically tired in the next session. Should I ask for TA support? 11/06/14

I feel guilty when
the client
withdraws from
MT

(Client) did not come today because she did not want to come to the group anymore... I also wondered whether (client) would have come if I accepted her request for my Korean song happily... if my uncomfortable feeling had influenced (client) in some way... 26/05/14 I am not prepared I wasn't ready to answer his question... I to respond to the internally went "uh oh" but tried to be calm and client clear as possible. $02 / 04 / 14$

I can feel not right (Client) always asks me to sing a Korean song. about responding I'm happy to do that every week if it was her to the client individual session, but in this group session, it doesn't feel always right to do that... 07/04/14

I can feel right about responding to the client ...I felt right to sing it this time, and I repeated the song twice. People listened to it and hummed along. 28/04/14

\begin{tabular}{|c|c|c|}
\hline $\begin{array}{l}\text { Different } \\
\text { feelings can } \\
\text { be } \\
\text { experienced } \\
\text { while } \\
\text { preparing for }\end{array}$ & $\begin{array}{l}\text { Regretting having } \\
\text { the session in an } \\
\text { inappropriate } \\
\text { space }\end{array}$ & $\begin{array}{l}\text { There was a piano and (liaising person) said } \\
\text { that nobody will interrupt. As soon as we began } \\
\text { the session, I regretted having the session at the } \\
\text { staff room because people came in and out } \\
\text { continuously and someone came in to use the } \\
\text { kitchen. } 04 / 06 / 14\end{array}$ \\
\hline MT sessions & $\begin{array}{l}\text { Regretting not } \\
\text { being clear with } \\
\text { the client and } \\
\text { having an } \\
\text { unexpected } \\
\text { session }\end{array}$ & $\begin{array}{l}\text { I think I should have (client A) only without } \\
\text { (client B) today. It was tricky to say no to } \\
\text { (client B) when he knew that (client A) is going } \\
\text { to have music. But after having a pair session } \\
\text { with them together I regretted for not having } \\
\text { individual session. Although they get along } \\
\text { well and play well together, I can see (client B) } \\
\text { is taking it over most of the time and (client A) } \\
\text { stays quite passive, which I think not very } \\
\text { helpful for (client A) when our goal is to }\end{array}$ \\
\hline
\end{tabular}


encourage his vocal and verbal interaction.

$18 / 06 / 14$

Getting upset

Unfortunately, all of the individual sessions

when a session is

cancelled without

prior notice

were cancelled without a notice. I was really

upset but I couldn't blame anyone because it

looked like it was a last minute decision for the

school as well to have those politicians in the

music room. 17/06/14

Feeling It feels like he avoids the ending of the

uncomfortable session... and his response makes me think

with the session

time

"Was I not clear enough?" I think I do need to

draw a time boundary for him. 18/03/14

The session with (client) tends to become like a

counselling session with full of dialogues... I

am also aware that the time is ticking...

$18 / 03 / 14$

Feeling I don't know if this idea came from my

uncomfortable personal anxiety... I think I was not very

with the session confident with staying with (client) without

structure

doing something. 25/03/14

Feeling uncertain I felt conscious about whether it was

about presenting appropriate to sing a waiata... or would it have

cultural material been better if I sang something different. $11 / 03 / 14$

Struggling with a When I work with (client) I feel anxious

client's because I feel like I really have to help him

contrasting needs finish in time but at the same time, I also want to really attend to what he is trying to tell me through music. 03/06/14 
Table 2.

Observing my own reactions as an SMT and interpreting clients' reactions

\begin{tabular}{|c|c|c|}
\hline \multicolumn{3}{|c|}{ Observing my own reactions as an SMT and interpreting clients' reactions } \\
\hline \multicolumn{2}{|c|}{ Findings } & Quotations from the journal \\
\hline \multirow[t]{8}{*}{$\begin{array}{l}\text { My reflections } \\
\text { on experience } \\
\text { in MT } \\
\text { practice }\end{array}$} & $\begin{array}{l}\text { Clients can } \\
\text { surprise me }\end{array}$ & $\begin{array}{l}\text { I am still wondering and being surprised by } \\
\text { how (client) have suddenly become active in } \\
\text { doing music... in my surprise, he actually } \\
\text { suggested to make an instrumental background } \\
\text { music! } 01 / 04 / 14\end{array}$ \\
\hline & $\begin{array}{l}\text { Client can } \\
\text { energise me }\end{array}$ & $\begin{array}{l}\text { When I see smiles and satisfied looks on their } \\
\text { faces, I feel really energised and rewarded... } \\
\text { 11/06/14 }\end{array}$ \\
\hline & $\begin{array}{l}\text { Client can help } \\
\text { me }\end{array}$ & $\begin{array}{l}\text { Before coming to the session, I worried about } \\
\text { bringing myself not quite ready or fully } \\
\text { prepared for them. It felt really different, } \\
\text { starting again with the things I already know } \\
\text { well, which now seemed quite new again... } \\
\text { and with a surprise, they started remind me of } \\
\text { some of the things we had been doing together. } \\
22 / 07 / 14\end{array}$ \\
\hline & $\begin{array}{l}\text { Client can } \\
\text { confuse me }\end{array}$ & $\begin{array}{l}\text { (Client) mentioned that she wanted to hear me } \\
\text { singing. So, does that mean she just likes my } \\
\text { voice or is it the tune that she's attracted to? I } \\
\text { am confused. } 07 / 04 / 14\end{array}$ \\
\hline & $\begin{array}{l}\text { New } \\
\text { understandings } \\
\text { about the client's } \\
\text { culture and health } \\
\text { conditions }\end{array}$ & $\begin{array}{l}\text { I am learning more and more about children } \\
\text { with Asperger's and their culture through } \\
\text { interacting with (clients). They both have } \\
\text { diagnosis of Asperger's but demonstrate a } \\
\text { totally different personality. The way they } \\
\text { engage themselves in the music, the way they } \\
\text { deal with and negotiate things, and the way } \\
\text { they receive and respond... are all very } \\
\text { different. } 27 / 05 / 14\end{array}$ \\
\hline & $\begin{array}{l}\text { New } \\
\text { understandings } \\
\text { about the client's } \\
\text { personality }\end{array}$ & $\begin{array}{l}\text { Most of the sessions with (client) are led by } \\
\text { him and he is usually in control of music. I } \\
\text { noticed that he likes to make things in order } \\
\text { and in line. He also likes to plan things so that } \\
\text { he can reference back... 27/05/14 }\end{array}$ \\
\hline & $\begin{array}{l}\text { New } \\
\text { understandings } \\
\text { about the client's } \\
\text { personality and } \\
\text { family }\end{array}$ & $\begin{array}{l}\text { (Client) is from Tonga... I don't know much } \\
\text { about Tongan culture but I could feel his sense } \\
\text { of being attentive and supportive from his peer } \\
\text { interaction. (Liaising person) mentioned that } \\
\text { (client) was brought up in the family where } \\
\text { they have a clear rule and regulations, and that } \\
\text { (client) would not show any signs of physical } \\
\text { discomfort until he actually reach the level he } \\
\text { cannot cope... 04/06/14 }\end{array}$ \\
\hline & $\begin{array}{l}\text { New } \\
\text { understandings }\end{array}$ & $\begin{array}{l}\text { I greeted (client) in her language for the first } \\
\text { time. When I greeted her, her face changed }\end{array}$ \\
\hline
\end{tabular}


about the client's

culture and

personality
Discovering new aspects of the client dramatically from calm/quiet to

delighted/overjoyed... She grabbed my hand and shook it gently as if saying "Good to see you". Looking back on that session, I've learnt that it was an appropriate way to communicate with her, and that she needed someone to reassure and support her cultural identity. I guess it's not just about learning their language but also about recognising their cultural value and finding the appropriate ways of communicating with them. 16/06/14 (Client) likes playing instruments and showing a good concentration. During the last few sessions, I have noticed that he tended to initiate a new activity when I acknowledge time to finish the session. It almost feels like he avoids the ending of the session.

$18 / 03 / 14$

During the individual session with (client), I found out another aspects of him. (Client) zoned out for quite a long period of time during the boomwhacker improvisation. He did not change the instrument or showed varieties in playing although I tried to tell him that he can do things differently. At the end, he seemed to find it difficult to finish the improvisation and kept on playing in the loop. He even yawned, but did not stop playing. It was very interesting to be in such playing. $27 / 05 / 14$

New learnings and insights about MT work in general
I keep thinking about the time with (client). We only had like six sessions which is not many, and then our relationship ended so suddenly... There were difficult moments but also fun and encouraging moments as well. It is not a pleasant feeling that I won't be able to see him again. However, I've learnt that you should always expect the unexpected and you need to keep going forward. 28/07/14

While working at (facility) I've learnt and still learning the value of the process in relationship. The process can be rather important than the outcome especially when you experience a sudden separation. 04/08/14 While I talked to (client), I somehow felt that he had a very low sense of control over the things around him. He often said "You do it" and "It's up to you". And when I told him he can choose and say yes/no, he responded "Well but it's gonna happen anyway"... After I had some experience at schools, I think the issue 


\begin{tabular}{|c|c|c|}
\hline & & $\begin{array}{l}\text { about a sense of control is quite different to } \\
\text { young people and elderly people. I think I'm } \\
\text { seeing young children 'developing' their sense } \\
\text { of control while the older adults 'restore' it. } \\
11 / 08 / 14 \\
\text { It is not easy to understand a person without } \\
\text { knowing their background and history. But on } \\
\text { the other hand, I didn't really need to know } \\
\text { about his family or history to build relationship } \\
\text { with him. I believe that we are building a good } \\
\text { trusting relationship. He opened himself up in } \\
\text { music. I really value his braveness. } 24 / 09 / 14\end{array}$ \\
\hline & $\begin{array}{l}\text { Working with } \\
\text { elderly people can } \\
\text { encourage my } \\
\text { cultural self }\end{array}$ & $\begin{array}{l}\text { Working with elderly people really encourages } \\
\text { me to appreciate my own culture and race. It is } \\
\text { getting clearer that I need to value and develop } \\
\text { my Korean culture and identity. } 10 / 03 / 14\end{array}$ \\
\hline & $\begin{array}{l}\text { I need to be more } \\
\text { proactive }\end{array}$ & $\begin{array}{l}\text { I need to make things clear to others so I can } \\
\text { protect the session time and the value in the } \\
\text { session with the clients. } 18 / 06 / 14\end{array}$ \\
\hline & $\begin{array}{l}\text { I need to be more } \\
\text { sensitive to } \\
\text { clients' needs and } \\
\text { in understanding } \\
\text { their capacities }\end{array}$ & $\begin{array}{l}\text { I think I overestimated her ability to control her } \\
\text { power or posture when playing instruments.... } \\
\text { I understand that it can be extremely difficult } \\
\text { for (client) to move her arms and hands as } \\
\text { flexibly as she want due to the specific physical } \\
\text { condition, and I am glad that she is still willing } \\
\text { to participate and play music. It's just that I } \\
\text { need to be more sensitive to her needs and } \\
\text { responses so that I can understand her better. } \\
23 / 07 / 14\end{array}$ \\
\hline & $\begin{array}{l}\text { Learning about } \\
\text { working in a } \\
\text { school } \\
\text { environment }\end{array}$ & $\begin{array}{l}\text { It's so upsetting and frustrating that you can't } \\
\text { use one space consistently.... It's a shame that } \\
\text { (liaising person) tells me those 'news' when I } \\
\text { actually arrive there, never gives me notice in } \\
\text { advance. I'm learning that it's common in } \\
\text { school environment where you can't really } \\
\text { expect things. } 18 / 06 / 14\end{array}$ \\
\hline $\begin{array}{l}\text { My proactive } \\
\text { reactions as } \\
\text { an SMT }\end{array}$ & $\begin{array}{l}\text { Making } \\
\text { suggestions and } \\
\text { taking initiatives }\end{array}$ & $\begin{array}{l}\text { As I did in the last session, I sat with him and } \\
\text { listened to him. (Client) talked more about } \\
\text { kakapo birds, and he was amazingly } \\
\text { knowledgeable about them. Here, I thought we } \\
\text { could write a song about kakapo birds, so I } \\
\text { suggested my idea to (client). He seemed } \\
\text { interested and asked me for a pen and paper. } \\
25 / 03 / 14 \\
\text { I went to (facility) and got everything ready in } \\
\text { the room. When I went to the classroom to get } \\
\text { the boys, their teacher said that they've gone to } \\
\text { the gardening. So, I went to see the boys down } \\
\text { the forest and said hello. They said they } \\
\text { thought that they didn't have music anymore. I }\end{array}$ \\
\hline
\end{tabular}


told them that it's cancelled today but we will

have it from next week. 23/07/14

Taking risks when

interacting with clients

When I played How Great Thou Art, I told

(client) that there is a Korean version of the

song and asked her if she wanted to hear it. She showed interest and nodded. She listened to it with her eyes fixed on me throughout the song. She might not understand Korean but I knew the meaning of lyrics was same. It was my first experience singing a hymn in Korean to nonKorean, and it felt quite nice because I was expressing my racial presence to (client) and I felt she recognised it. 05/05/14

Trying to Working with elderly is different to that of understand and learn about clients young children in terms of their conditions and life circumstances... I'm trying my best to understand how they might be feeling. I also read books and literatures about dementia and palliative care, but I still feel insufficient in understanding their feelings and experiences. $14 / 04 / 14$

Trying to understand and learn about clients by thinking from the client's perspective At the end of our first pair session, (client) asked me why he and (his peer) was doing this with me... This question stayed in my head and made me ask myself "Why are we doing this?" Perhaps (client) felt uncomfortable about the fact that it was only him and his peer who went out of the classroom (being selected?). $02 / 04 / 14$

Trying to I feel anxious and often think "When is this understand and going to finish? I need to acknowledge the learn about clients end!" And at the same time I feel sorry for not by questioning really focusing and listening to what he might myself be trying to tell me... Or is he feeling the same anxiety as mine? Is that why he cannot expand his playing into the longer musical interaction because he felt anxious about the time? Is my anxiety affecting the way he express himself? 03/06/14

Seeking I talked to one of the therapists at the centre, professional advices and she said that it is quite common for people and especially those with ASD. She suggested to ask teachers whether he finds it difficult to engage/interact with his peers at lunchtime. $18 / 03 / 14$ I brought a video clip of the session with (client) because I wanted to hear from (clinical supervisor) how she think about this session and discuss my 'self-conscious' responses during the session. It was very helpful to hear 


\begin{tabular}{|c|c|c|}
\hline & & $\begin{array}{l}\text { from the third person and things began to find } \\
\text { their place. } 01 / 04 / 14\end{array}$ \\
\hline \multirow[t]{4}{*}{$\begin{array}{l}\text { My } \\
\text { submissive } \\
\text { reactions as } \\
\text { an SMT }\end{array}$} & Being passive & $\begin{array}{l}\text { (Client) always asks me to sing Korean song. I } \\
\text { really appreciate her genuine interest in my } \\
\text { culture and songs. Somehow I tend to look for } \\
\text { some sort of approval from (MTh) whether I } \\
\text { should step in and sing it. } 10 / 03 / 14\end{array}$ \\
\hline & $\begin{array}{l}\text { Being submissive, } \\
\text { can't say no }\end{array}$ & $\begin{array}{l}\text { I don't feel comfortable when (client) insists } \\
\text { me to sing. It is very challenging especially } \\
\text { because I'm from Asian culture where you } \\
\text { can't really say no to the elderly. } 07 / 04 / 14 \\
\text { I think I should have (client A) only without } \\
\text { (client B) today. It was tricky to say no to } \\
\text { (client B) when he knew that (client A) is going } \\
\text { to have music. } 18 / 06 / 14\end{array}$ \\
\hline & $\begin{array}{l}\text { Being careful in } \\
\text { "pushing" clients }\end{array}$ & $\begin{array}{l}\text { I remembered that he would avoid to sit on the } \\
\text { ground because that will take a lot of time and } \\
\text { effort for him to sit down and stand up again... } \\
\text { I didn't want to make him feel isolated or } \\
\text { different to other kids... We played the musical } \\
\text { hide and seek and he even sat down on the } \\
\text { ground to hide himself effectively. I was very } \\
\text { surprised when he did that. I suppose I wasn't } \\
\text { confident enough to encourage him to do that } \\
\text { sort of things after he said he didn't want to sit. } \\
23 / 07 / 14\end{array}$ \\
\hline & $\begin{array}{l}\text { Being careful in } \\
\text { responding to } \\
\text { clients }\end{array}$ & $\begin{array}{l}\text { (Client) looks so happy and excited when he } \\
\text { talks about kakapo birds, and in this situation } \\
\text { there's not much I can do other than listening } \\
\text { to him. I don't feel that redirecting the issue } \\
\text { will help - it might actually cause his anxiety. I } \\
\text { sat with him and listened to him. } 25 / 03 / 14\end{array}$ \\
\hline \multirow{3}{*}{$\begin{array}{l}\text { My } \\
\text { involuntary } \\
\text { reactions } \\
\text { towards my } \\
\text { clients }\end{array}$} & $\begin{array}{l}\text { Having fixed } \\
\text { perceptions about } \\
\text { the client }\end{array}$ & $\begin{array}{l}\text { (Client) is a religious woman and I used to sing } \\
\text { a lot of hymns with her. She would usually } \\
\text { respond positively to the hymns. } 09 / 06 / 14\end{array}$ \\
\hline & $\begin{array}{l}\text { Experiencing a } \\
\text { personal struggle } \\
\text { with cultural } \\
\text { issues of 'age' } \\
\text { and 'respect' }\end{array}$ & $\begin{array}{l}\text { I don't feel comfortable when (client) insists } \\
\text { me to sing. It is very challenging especially } \\
\text { because I'm from Asian culture where you } \\
\text { can't really say no to the elderly. } 07 / 04 / 14\end{array}$ \\
\hline & $\begin{array}{l}\text { Being resistant to } \\
\text { clients' } \\
\text { authoritative } \\
\text { behaviour }\end{array}$ & $\begin{array}{l}\text { I don't feel comfortable when (client) insists } \\
\text { me to sing... She is very nice woman and I } \\
\text { know she didn't mean to do that, but I often get } \\
\text { the feeling that she's being authoritative and } \\
\text { assertive. } 07 / 04 / 14\end{array}$ \\
\hline $\begin{array}{l}\text { Proactive } \\
\text { reactions of } \\
\text { clients }\end{array}$ & $\begin{array}{l}\text { Showing interest } \\
\text { in my culture }\end{array}$ & $\begin{array}{l}\text { (Client) always asks me to sing Korean song. I } \\
\text { really appreciate her genuine interest in my } \\
\text { culture and songs. } 10 / 03 / 14 \\
\text { When I played How Great Thou Art, I told } \\
\text { (client) that there is a Korean version of the }\end{array}$ \\
\hline
\end{tabular}


song and asked her if she wanted to hear it. She showed interest and nodded. She listened to it with her eyes fixed on me throughout the song. $05 / 05 / 14$

Sharing their own interests with me as an SMT
(Client) likes to share his special interest in NZ extinct birds. 18/03/14

(Client) looks so happy and excited when he talks about kakapo birds... I sat with him and listened to him... (Client) talked more about kakapo birds, and he was amazingly knowledgeable about them. 25/03/14

Showing respect When we sang hello song (client) wanted to to other cultures sing it in Chinese although he didn't know how to say hello in Chinese... I suppose he thought I was from China. I felt that he was showing cultural respect by suggesting the group to sing hello in Asian language. 16/04/14

Being a leader (Client) and I spent most of the time exploring and combining different instruments. This time, it was not me who led the music but it was (client) who was the leader and a conductor of his own music. 01/04/14

$\begin{array}{cl}\text { Client } & \text { Expressing a } \\ \text { responds } & \text { sense of } \\ \text { naturally } & \text { ownership }\end{array}$
We finished writing a song about kakapo today... I suggested (client) that I could burn a disc of this music if he is happy. (Client) said it was a good idea and that I could also keep a copy if I want to. This surprised me because I had an unconscious thought that this music was our joint product. I felt a bit embarrassed for making assumption, and at the same time was happy that he had a sense of ownership of his own music. 15/04/14

Showing a strong I greeted (client) in her language for the first emotional reaction and time. When I greeted her, her face changed dramatically from calm/quiet to physical affection delighted/overjoyed. I greeted her again and she nodded gently with a teary face, but somehow she did not look sad. She looked surprised like "oh!" when I greeted her in her language... She grabbed my hand and shook it gently as if saying "Good to see you". 16/06/14

Exhibiting transference of own desire (Client) loves drawing on the board and we spent most of our time to draw and play instrument about the pictures. When he finished drawing, he asked me to take photo and said "Do you know my mum's phone number?" I said no and he told me he knew it and asked me to send this photo to his mum. Then I remembered from the IEP meeting that his mum was working and busy that they rarely 
see each other during the day. He spends the most of his time with his nanny (his $6^{\text {th }}$ nanny). Because I knew his story, I felt I really wanted to give this feedback to his mum and show her his drawings. It seemed as if (client) was trying so hard to make connection with his mum. 29/07/14 
Table 3.

Making connections and disconnections with clients

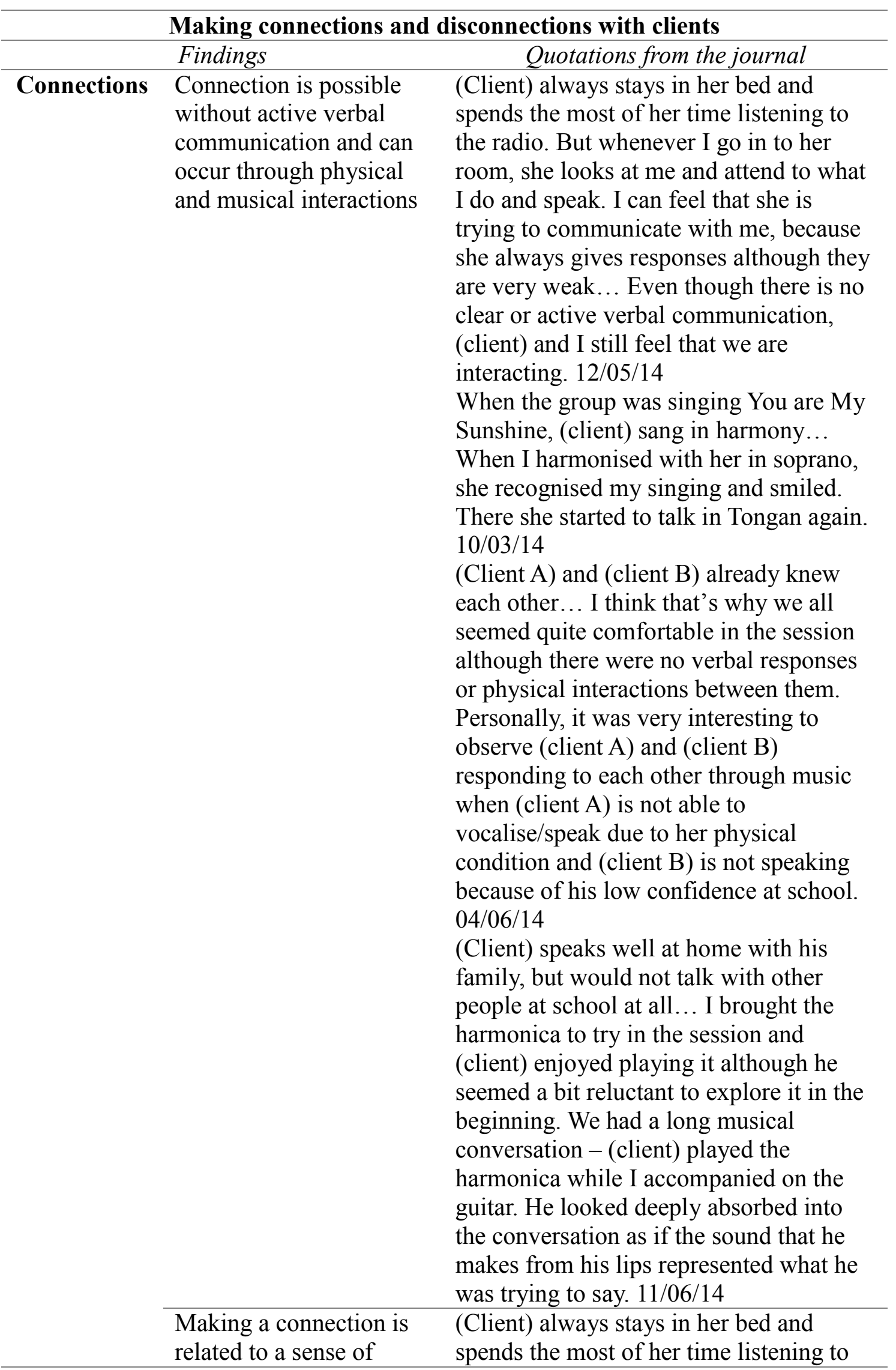


mutuality and

responsiveness the radio. But whenever I go in to her

room, she looks at me and attend to what I do and speak. I can feel that she is trying to communicate with me, because she always gives responses although they are very weak. It's like both of us are trying really hard to make connection to each other. 12/05/14

Emotional connections can be formed through "being with"

(Client) likes to share his special interest in NZ extinct birds. It's great that he finds this place comfortable and safe to share his personal stories and interests. I sit with him and listen, and respond with "Ahh" and "really?" Then he continues with his story. 18/03/14

I can't seem to find any life will from (client) - he doesn't move a step out of his box... When I finished playing some songs, I asked him if he felt tired. He said yes. I asked him what made him feel tired, and he said "looking at you"... I suppose it can be demanding for him to be with someone else even if we are not doing anything physical. But then it is also quite demanding for me to be in such heavy and depressing situation. I guess I don't know what to 'do' with him. I feel like I have to do something meaningful with him... Sometimes we underestimate the importance of just being with them. We tend to forget the value of walking alongside someone. 16/06/14

Greeting in a culturally specific way can lead to the making of connections and the appreciation of another culture
I greeted (client) in her language for the first time. When I greeted her, her face changed dramatically from calm/quiet to delighted/overjoyed. I greeted her again and she nodded gently with a teary face, but somehow she did not look sad. She looked surprised like "oh!” when I greeted her in her language... She grabbed my hand and shook it gently as if saying "Good to see you". We had a good time singing and playing together. Looking back on that session, I've learnt that it was an appropriate way to communicate with her, and that she needed someone to reassure and support her cultural identity. I guess it's not just about learning their language but also about recognising their cultural value and 


\begin{tabular}{|c|c|c|}
\hline & & $\begin{array}{l}\text { finding the appropriate way of } \\
\text { communicating with them. } 16 / 06 / 14\end{array}$ \\
\hline \multirow[t]{2}{*}{$\begin{array}{l}\text { Disconnectio } \\
\text { ns }\end{array}$} & $\begin{array}{l}\text { Disconnection can take } \\
\text { place in different ways; } \\
\text { physical, musical, and } \\
\text { emotional }\end{array}$ & $\begin{array}{l}\text { (Client) zoned out for quite a long period } \\
\text { of time during the boomwhacker } \\
\text { improvisation. He did not change the } \\
\text { instrument or showed varieties in playing } \\
\text { although I tried to tell him that he can do } \\
\text { things differently... He even yawned, but } \\
\text { did not stop playing. It was very } \\
\text { interesting to be in such playing. } \\
27 / 05 / 14 \\
\text { With (client), I only had one session out } \\
\text { of five. I'm not sure whether I need to } \\
\text { work with her as she finds it extremely } \\
\text { difficult to get to the MT room, and it's } \\
\text { tricky for me to make connection with } \\
\text { her... } 11 / 06 / 14 \\
\text { When the group plays "boys game" I feel } \\
\text { a bit isolated and left out... All I could do } \\
\text { is just to accompany their playing on the } \\
\text { guitar - playing Em and Am powerfully } \\
\text { as if telling them 'I'm here and I want to } \\
\text { join!" Then they would include me in } \\
\text { their battle field. } 11 / 06 / 14 \\
\text { (Client) doesn't say anything, and I've } \\
\text { never seen him talking to other people. } \\
\text { He indicates yes/no through gestures... } \\
\text { He doesn't seem to have desire to } \\
\text { communicate. I almost feel like he's } \\
\text { saying to me "Just do whatever you like } \\
\text { but don't touch me.” It's just me who's } \\
\text { trying to make connection; one-sided } \\
\text { relationship. It feels like the door is } \\
\text { almost closed between us, and I can't } \\
\text { seem to find a space to be connected with } \\
\text { him. } 12 / 05 / 14\end{array}$ \\
\hline & $\begin{array}{l}\text { Endings can be either } \\
\text { prepared or unpredictable }\end{array}$ & $\begin{array}{l}\text { I was worrying about (client) becoming } \\
\text { anxious or even upset about ending. But } \\
\text { (client) managed it really well, and he has } \\
\text { made the most of his final music time... } \\
\text { Towards the end of the session, it seemed } \\
\text { as if (client) was trying to use all of his } \\
\text { energy into the session and he made } \\
\text { himself exhausted. I let him do that and } \\
\text { did not stop him from jumping and } \\
\text { dancing rigorously around the room } \\
\text { because I felt that that was his way of } \\
\text { ending and processing the final moment. } \\
\text { When we all finished, (client) took off the } \\
\text { whole countdown chart from the board }\end{array}$ \\
\hline
\end{tabular}


and threw it in the air as if celebrating

it... Ending and separation can be a "not too difficult thing" when it's prepared and predicted. 23/09/14

It already has been a month now and I'm back again. I passed by (client) bedroom but he wasn't there. I couldn't find him until it was time to see him individually. I asked one of the staffs and he told me that (client) passed away last Friday. I was very shocked, still can't really believe it... It was a shock especially because this happened when I was away. It all happened suddenly. 21/07/14

Language barriers (i.e. client speaking another language, barriers in understanding clients and their culture) and my low confidence in English can challenge the development of the relationship
During the group session, a Tongan woman was talking to others in Tongan although she could speak English... I thought she was trying to tell us 'back in the days' or her own story. 10/03/14 I sometimes find it a bit difficult to find a word or a way to explain/describe things in English, especially when I work with young children. It's probably because I don't have much experience working with young children whose first language is English. There seems to be another language for young children... 15/04/14 I tend to slow it down when I feel I'm getting lost, but I still find it extremely difficult with being spontaneous in speaking English. This sometimes affects the way I sing and improvise - it just doesn't come out as naturally as in Korean.15/04/14 
Table 4.

Learning to adapt and refine the use of MT methods

\section{Learning to adapt and refine the use of MT methods}

\begin{tabular}{cl}
\hline & Findings \\
\hline Using MT & Matching and reflecting a \\
methods to & client's experience and \\
support a & culture by writing songs \\
client's & about the client's special \\
cultural & interest \\
identity &
\end{tabular}

Quotations from the journal

As I did in the last session, I sat with him and listened to him. (Client) talked more about kakapo birds, and he was amazingly knowledgeable about them. Here, I thought we could write a song about kakapo birds, so I suggested my idea to (client). He seemed interested and asked me for a pen and paper. 25/03/14 We finished writing the lyrics for our kakapo song today, and I told him we could either use his favourite tune or make up a new melody. (Client) choose to make up a new one and in my surprise, he actually suggested to make an instrumental background music! (Client) and I spent most of the time exploring and combining different instruments. This time, it was not me who led the music but it was (client) who was the leader and a conductor of his own music. 01/04/14

We finally completed writing a song about kakapo today. We recorded all our instrumental combinations into the iPhone application called "loop" and had fun playing it while reading aloud the lyrical passages. 15/04/14

Supporting a client's cultural identity by adapting culturally specific songs
Before we finished, I introduced a new song for our closing song that I prepared for (client). I used a tune from the Samoan song Savalivali, hoping I could make another connection with her. Although the lyrics were adapted for our closing routine, (client) was still listening to it. She did not seem to be agitated by it... I am not aware of how closely connected she is to her culture, but I believed that bringing music from her culture would reassure her that she still have this connection to her culture and people even though she loses other close connections such as religious belief or even her physical conditions. 09/06/14

Empowering my client's Unlike the previous sessions, I really cultural self and sense of wanted to encourage him to make choices 
control by offering

choices of MT activities so that he have the sense of control.

When I asked him about the songs I brought, (client) said no by shaking his head. I invited him to listen and told him that he might know them if he listen... When I started playing the songs, (client) changed his face and expressed sadness and despair. He almost grimaced his face that made him look really weary. I could really feel he was emotionally responding to music. $09 / 06 / 14$

While I talked to (client), I somehow felt that he had a very low sense of control over the things around him. He often said "You do it" and "It's up to you". And when I told him he can choose and say yes/no, he responded "Well but it's gonna happen anyway" I thought he saw me as someone physically more able and therefore had more power to make decisions than he could. 11/08/14

$\begin{array}{cl}\text { Adapting } & \text { Free and thematic } \\ \text { different } & \text { improvisations can } \\ \text { facilitating } & \text { encourage musical and } \\ \text { skills in MT } & \text { verbal interactions } \\ \text { sessions } & \end{array}$
I brought the harmonica to try in the session and (client) enjoyed playing it although he seemed a bit reluctant to explore it in the beginning. We had a long musical conversation - (client) played the harmonica while I accompanied on the guitar. He looked deeply absorbed into the conversation as if the sound that he makes from his lips represented what he was trying to say. I was really excited when (client) picked up the harmonica. He looked at me for reassurance which I provided verbally. He was happy to explore the harmonica and he used different breathing techniques without being anxious or worried. 11/06/14 During the improvisation on the xylophone, (client) said it was hard to think of what/how to play it. I suggested to try not to think ad play. He was happy to explore this and had a few turns on both "think" and "not think" playing. When we finished, he commented that it was difficult to not to think and play too... I was happy to see (client) trying to explore those (doing things differently) and communicating his feelings about it. $12 / 08 / 14$ 
Offering music can be useful when initiating interactions
I had the first individual session with (client) in her room... I introduced myself and asked if I could play some songs... I sat beside her and sang a few hymns on the guitar. She would vocalise a few times. When I played How Great Thou Art, I told (client) that there is a Korean version of the song and asked her if she wanted to hear it. She showed interest and nodded. She listened to it with her eyes fixed on me throughout the song. 05/05/14

Adjusting and choosing appropriate instruments is important when working with clients who have reduced physical capacities

(Client) liked the table hand bells and played them powerfully. Eventually, she hurt her hands by pressing the bells too hard. I think it was good to introduce the bells to (client) because it was something she could do. However, I think I overestimated her ability to control her power or posture when playing instruments. After observing (client) playing the hand bells and other percussive instruments, it seemed more sensible to provide softer instruments and also help her to control her power. 23/07/14

Finding and keeping the right space for MT is important in protecting the client's safety and maintaining consistency in the relationship
One of the challenges ad (facility) is finding the right space for the MT session. I had a session with (clients) as a pair for the first time at the staff room. There was a piano and (liaising person) said that nobody will interrupt. As soon as we began the session, I regretted having the session at the staff room because people came in and out continuously and someone came in to use the kitchen. It wasn't helpful for (clients) especially it was their first meeting. I also felt sorry for (client) as he became rigid and anxious in the session. 04/06/14 It was so challenging to set up the room today as there was a group of children and teachers making something in front of the music room, which made a lot of noises. I had to bring all the instruments from the cupboard and carry them to another room which was across the music room. I only managed carry little drums and a gathering drum, but not harmonic instruments except the guitar. During the 
session, I felt so impressed that (client) was able to show some flexibility in setting up the timetable using the only instruments we had, because he usually travels around the room to find his own instruments when we're in the music room. 10/06/14 